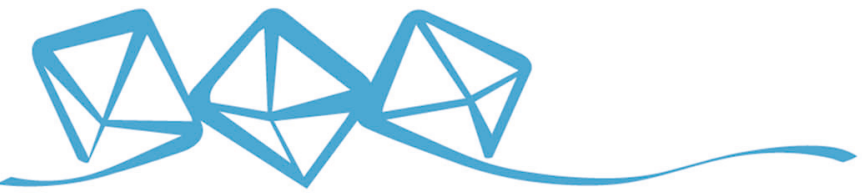 COMMUNICATIONS MATERIALS
}

ARTICLE

https://doi.org/10.1038/s43246-020-00089-9 OPEN

\section{Recombinant collagen polypeptide as a versatile bone graft biomaterial}

Hideo Fushimi (1) ${ }^{1,3 凶}$, Takahiro Hiratsuka ${ }^{1,3}$, Ai Okamura ${ }^{1}$, Yoshitaka Ono ${ }^{1}$, Izumi Ogura ${ }^{1}$ \& Ichiro Nishimura ${ }^{2}$

Autografts and allografts are currently considered the gold standard for grafting surgery; however, to meet the growing demand in fast-aging societies, synthetic biomaterials will play an increasingly important role. Here we report a biodegradable scaffold material composed of recombinant polypeptide based on the human type I collagen alpha 1 chain (RCPhC1) as a source of hydrogel-based graft materials. The flexibility to engineer ideal characteristics for bone grafts was demonstrated. The critical internal isotropic pore structure was generated through a designed thin-layer freeze casting process. The optimized biodegradation rate was controlled by dehydrothermal crosslinking by adjusting the amino acid composition of $\mathrm{RCPhC1}$. As a result, $\mathrm{RCPhC1}$ bone grafts manufactured by a highly scalable streamlined production protocol induced robust regeneration of mature bone tissue while being completely resorbed in pre-clinical animal models.

\footnotetext{
${ }^{1}$ Bio Science \& Engineering Laboratory, Research \& Development Management Headquarters, FUJIFILM Corporation, 577, Ushijima, Kaisei-machi, Ashigarakami-gun, Kanagawa 258-8577, Japan. ${ }^{2}$ Weintraub Center for Reconstructive Biotechnology, UCLA School of Dentistry, Box 951668 CHS B3-087, Los Angeles, CA 90095, USA. ${ }^{3}$ These authors contributed equally: Hideo Fushimi, Takahiro Hiratsuka. ${ }^{凶}$ email: hideo.fushimi@fujifilm.com
} 
T he loss of tissue volume and its specific function is a hallmark of the pathological challenges of injury, chronic inflammation, and tumor ablation surgery, as well as of metabolic and genetic diseases. Severe bone loss is one of the most frequently experienced disease complications. Bone tissue actively regenerates its voids through proliferation and osteogenic differentiation of resident mesenchymal stromal/stem cells through available regulatory signals ${ }^{1}$. However, larger bone defects or pathological fracture often require surgical intervention to repair and rebuild diseased or damaged bone with appropriate bone graft materials ${ }^{2}$. Approximately 2.2 million bone graft procedures are performed annually in the world ${ }^{3}$. The global market for bone grafts and substitutes now exceeds US $\$ 2.5$ billion, including over US $\$ 500$ million for dental and craniofacial applications ${ }^{4}$.

Human bone tissue is composed of organic extracellular matrix (ECM) and crystallized calcium and phosphorus minerals forming hydroxyapatite. Bone graft materials are designed to mimic the structure or biochemical components of bone tissue. Autologous bone graft has been used for bone defects due to its combined osteogenic property and minimal immunological/ infectious concerns ${ }^{5}$. However, limited availability and complications at the donor site have deterred the widespread use of autologous bone graft. Allografts are considered the primary alternative bone graft material ${ }^{6}$. Decellularized bone allografts exhibit the physical property of cancellous bone that maintains interconnecting porosity reaching $50-90 \%$. The interconnecting porosity increases the surface area of these grafting materials and is considered beneficial for bone ingrowth ${ }^{7}$. Demineralized bone allograft is a biodegradable natural polymer primarily composed of bone collagen ECM, which provides a scaffold for cellular migration and tissue regeneration ${ }^{8}$.

Bone graft procedures are expected to increase in line with bone-related injuries and diseases in fast-aging societies. In the last decade, decellularized and demineralized bone allografts have rapidly increased to become the primary choice of bone graft materials, accounting for one-third of all bone grafts performed in the US ${ }^{9}$. However, the supply of bone allografts may not keep pace with the projected demand for bone grafts and substitutes in the future. While the risk is small, concerns regarding individual inconsistency of allografts and possible disease transmission have not been completely eliminated ${ }^{10}$. Therefore, there is an urgent need to develop new bone graft materials without using human or animal tissue for the healthcare industry.

Synthetic bone graft materials are available; however, their efficacy has not been fully established in various applications ${ }^{6,11,12}$. The major challenge includes inflexibility of engineering control in bone mineral substitutes such as hydroxyapatite and calcium phosphate materials as well as synthetic polymer materials. Here we report a recombinant polypeptide based on the human type I collagen alpha 1 chain with sequence modifications (RCPhC1), which was developed to be a versatile source material highly suitable for flexible engineering controls to manufacture synthetic bone graft. RCPhC1-based bone graft was produced as highly porous granules with optimized biodegradation rate. Preclinical studies using rodent and canine bone defects demonstrated the high efficacy of RCPhC1 bone graft, which rapidly regenerated sizable bone tissue with structural maturity.

\section{Results}

Recombinant polypeptide based on human type I collagen alpha 1 chain (RCPhC1). Type I collagen is one of the most abundant proteins widely expressed in connective tissues and interstitial membranes, and is also the major organic component of bone tissue ${ }^{13}$. The proper protein sequence of type I collagen plays an integral role in the mechanical strength of bone $e^{14,15}$. Natural hydrogel products for a wide range of medical and cosmetic applications contain type I collagen of animal origin such as bovine, porcine or marine (fish) ${ }^{16}$. We set out to design medically relevant recombinant type I collagen polypeptide.

The protein sequence of human type I collagen alpha 1 chain from 716 to 779 (GenBank P02452) was used to design RCPhC1. Four overlapping collagenous fragments of 716-757, 722-772, 731-778, and 722-769 were fused to construct a core peptide, which was then tandemly repeated. This molecular design resulted in the increase of Lys, an amino acid residue that is critical for dehydrothermal crosslinking in downstream engineering flexibility (Table 1). To prevent undesired post-translational modification by the host yeast strain Pichia pastoris, amino acid residues $\mathrm{Thr}$ and Ser were substituted by Leu or Ala. Furthermore, selected Asp residues were substituted by Glu to prevent protein degradation. As a result, $\mathrm{RCPhC1}$ is composed of 571 amino acid residues with repeated Gly-X-Y (Fig. 1a). Due to amino acid substitutions, the $\mathrm{RCPhC1}$ sequence is not identical to the original fragment of human type I collagen alpha 1 chain (716-779). The pentapeptide unit is a common minimal amino acid sequence critically involved in peptide-protein interaction and immune recognition ${ }^{17}$. Accordingly, the core fragment of $\mathrm{RCPhC1}$ was screened for sequence homology and it was found that pentapeptides including all amino acid substitutions matched the human collagen amino acid sequences (Fig. 1a). Thus, RCPhCl is considered not to possess immunogenicity.

The cDNA encoding RCPhC1 was cloned into pPICZ expression vector (Supplementary Table 1) and transfected to Pichia pastoris to generate master and working cell banks. $\mathrm{RCPhCl}$ was synthesized in a good manufacturing practice (GMP) facility. The amino acid composition of the synthesized $\mathrm{RCPhC1}$ was confirmed to be as designed. RCPhC1 lacked Thr and Ser residues and increased Lys residues as compared to commercially available porcine, bovine and marine (fish) collagen/gelatin materials (Table 1).

The genetic stability of the working cells was determined in genomic DNA, which maintained its fidelity after each of four repeated fermentations (Fig. 1b). Three batches of $\mathrm{RCPhC1}$ were analyzed by liquid chromatography. There were three distinct reverse-phase peaks that were found to carry oxidized Met residues. The separate batches of $\mathrm{RCPhC1}$ produced identical reverse-phase peaks (Fig. 1c), confirming the reproducibility of recombinant peptide synthesis. The reproducibility of $\mathrm{RCPhCl}$ synthesis was also determined using these separate batches by sodium dodecyl sulfate-polyacrylamide gel electrophoresis (SDS-PAGE), which showed a consistent single band of $63 \mathrm{kDa}$ (Fig. 1d). The calculated molecular weight of $\mathrm{RCPhC1}$ was $51 \mathrm{kDa}$. We further determined the molecular weight of RCPhC1 by electrospray ionization-mass spectrometry. The result indicated the molecular weight to be $51,189 \pm 30 \mathrm{Da}$. Therefore, the molecular weight discrepancy in SDS-PAGE was not caused by post-translational modification but was thought to be due to the basic nature of $\mathrm{RCPhCl}$ protein.

Pichia pastoris is a commonly used organism for the high-level production of recombinant proteins ${ }^{18,19}$. However, Asn-Xaa-Ser/ Thr sequences are often subjected to post-translational glycosylation $^{20}$, which has been shown to increase immunogenicity of recombinant products ${ }^{21-24}$. $\mathrm{RCPhC1}$ is not a glycoprotein by design and its sequence does not include Thr and Ser. We carried out carbohydrate content analysis to ensure the absence of glycosylation (Fig. 1e). The manufactured $\mathrm{RCPhCl}$ was confirmed by gel permeation chromatography to be highly purified (Fig. 1f). 
Table 1 Amino acid composition of RCPhC1 and commercially available porcine, bovine, and marine (fish) collagen/gelatin products.

\begin{tabular}{|c|c|c|c|c|c|}
\hline Amino acid & RCPhC1 (\%) & Porcine skin (\%) & Bovine skin (\%) & Bovine bone (\%) & Marine (Fish) (\%) \\
\hline Gly & 33.5 & 33.0 & 33.2 & 33.5 & 34.2 \\
\hline Ala & 15.4 & 11.2 & 11.2 & 11.7 & 12 \\
\hline Val & 1.6 & 2.6 & 2.0 & 2.2 & 1.9 \\
\hline Leu & 5.8 & 2.4 & 2.3 & 2.4 & 2.1 \\
\hline Ile & 1.1 & 1.0 & 1.2 & 1.1 & 0.9 \\
\hline Ser & 0.0 & 3.5 & 3.6 & 3.3 & 3.5 \\
\hline Thr & 0.0 & 1.8 & 1.7 & 1.8 & 3 \\
\hline Asp & 5.8 & 4.5 & 4.6 & 4.7 & 4.3 \\
\hline Gln & 2.1 & 0.0 & 0.0 & 0.0 & 0.0 \\
\hline Glu & 4.2 & 7.2 & 7.1 & 7.3 & 5.7 \\
\hline Cys & 0.0 & 0.0 & 0.0 & 0.0 & 0.0 \\
\hline Met & 1.6 & 0.4 & 0.6 & 0.4 & 1.0 \\
\hline Lys & 5.8 & 2.7 & 2.8 & 2.8 & 2.7 \\
\hline Hyl & 0.0 & 0.6 & 0.6 & 0.4 & 0.6 \\
\hline Arg & 5.8 & 4.9 & 4.6 & 4.8 & 5.4 \\
\hline His & 0.0 & 0.4 & 0.5 & 0.4 & 0.4 \\
\hline Phe & 0.0 & 1.3 & 1.2 & 1.4 & 1.4 \\
\hline Tyr & 0.0 & 0.3 & 0.2 & 0.1 & 0.2 \\
\hline Pro & 17.5 & 13.1 & 12.9 & 12.4 & 13.3 \\
\hline Hyp & 0.0 & 9.1 & 9.7 & 9.3 & 7.4 \\
\hline
\end{tabular}

The RCPhC1 production process and its protein structure were extensively characterized elsewhere ${ }^{25-27}$ (Supplementary Tables 2-5 and Supplementary Figs. 1 and 2). It must be noted that RCPhC1 lacked N- and C-terminal telopeptides. During the natural collagen fiber formation, the C-terminal telopeptide provides the helix nucleation, alignment and propagation of collagen triple helix super structure ${ }^{28}$. As anticipated, $\mathrm{RCPhC1}$ did not form triple helix structure at $37^{\circ} \mathrm{C}$ as Circular Dichroism at $230 \mathrm{~nm}$ showed negative rotation (Supplementary Fig. 2).

Thin-layer freeze casting (TLFC) for isotropic ice-templated structures. The internal structure of graft materials is an important engineering factor to attain the specific requirement of the target tissue ${ }^{29}$. Collagen, gelatin and other hydrogel materials have been processed through a combination of freeze casting and dehydrothermal crosslinking ${ }^{30}$. Freeze casting can produce various internal pore structures templated by ice crystals. The set cooling rate, final set freezing temperature and freezing time are the primary controlling factors of ice nucleation and crystallization $^{31}$. The conventional freeze casting protocol uses a freezer block (Fig. 2a), which generates different cooling profiles at the bottom of the cooling cup and the solute surface (Fig. 2b). This discrepancy in freezing profile results in unidirectional solidification in the direction of depth of the cooler cup and anisotropic internal structure ${ }^{32-34}$ (Fig. 2c). Target tissues such as tendon and peripheral nerve possess an extracellular matrix with an inherent anisotropic structure, which has been regenerated by hydrogel scaffolds with anisotropic internal structure ${ }^{35-37}$. In our study, the anisotropic ice-templated pore structure was found to be associated with a zone of submicron pores at the bottom of the cooler cup (Fig. 2c). RCPhC1 sponge with submicron pore structure prohibited cell migration and bone formation in a rat calvarial bone defect model ${ }^{38,39}$ (Supplementary Fig. 3).

Nucleation is stochastic by nature; however, ice crystal growth is sensitive to the heat flow within the system. The heterogeneity in pore structures by the conventional ice-template process is thought to be due to the different freezing characteristics between the solute surface and the bottom of the cooler cup. To generate a uniform and isotropic pore structure, we designed a thin-layer freeze casting (TLFC) protocol. TLFC generated a similar freezing profile at the solute surface and the bottom of the container (Fig. 2d). As a result, isotropic pores were formed while preventing the submicron pore structure at the bottom. Due to the minimized heat flow within the system, TLFC was able to simplify the engineering control factor as described below.

First, the effect of cooling duration and minimum temperature was evaluated for the development of uniform pores (Fig. 2e). It was suggested that a minimum temperature of $-10{ }^{\circ} \mathrm{C}$ or less contributed to pore uniformity, which was not affected by cooling duration (Fig. 2e). Next, the pore size distributions were evaluated for the cooling block temperature. When the cooling block temperature was set below $-60{ }^{\circ} \mathrm{C}$, small pores of less than $100 \mu \mathrm{m}$ tended to form (Fig. 2f). Scaffold materials with small pores of average diameter between $10 \mu \mathrm{m}$ and $100 \mu \mathrm{m}$ were reported to prevent skin wound contraction ${ }^{29}$. By contrast, the optimal pore size of scaffold materials supporting skeletal tissue regeneration was reported to be $210 \pm 40 \mu \mathrm{m}^{40}$ and $250-420 \mu \mathrm{m}^{41}$. Therefore, a tissue-specific RCPhC1 scaffold may be fabricated by controlling the cooling block temperature. Finally, the effect of engineering protocols on the porosity and thickness of the RCPhC1 scaffold was evaluated by water absorption rate and acid decomposition rate. The TLFC appeared to generate a larger number of pores with thin walls as indicated by the larger water absorption rate and acid composition rate (Fig. 2g). The conventional anisotropic structure appeared to be less porous with thick walls as indicated by the smaller water absorption rate and acid composition rate. RCPhC1 scaffold subjected to mechanical stirring generated forms, which showed different characteristics that resisted acid decomposition (Fig. $2 \mathrm{~g}$ ). Taken together, we developed a versatile freeze casting protocol to generate $\mathrm{RCPhC1}$ scaffold having various internal structures.

Dehydrothermal crosslinking profile. Collagen-based scaffolds are crosslinked to varying degrees, and the degree of crosslinking controls the mechanical strength ${ }^{42,43}$ and biodegradation rate ${ }^{44}$. Various crosslinking methods have been reported including hydrothermal, chemical, and photochemical treatments ${ }^{45,46}$. In this project, after the TLFC process, the ice crystals were removed 
a

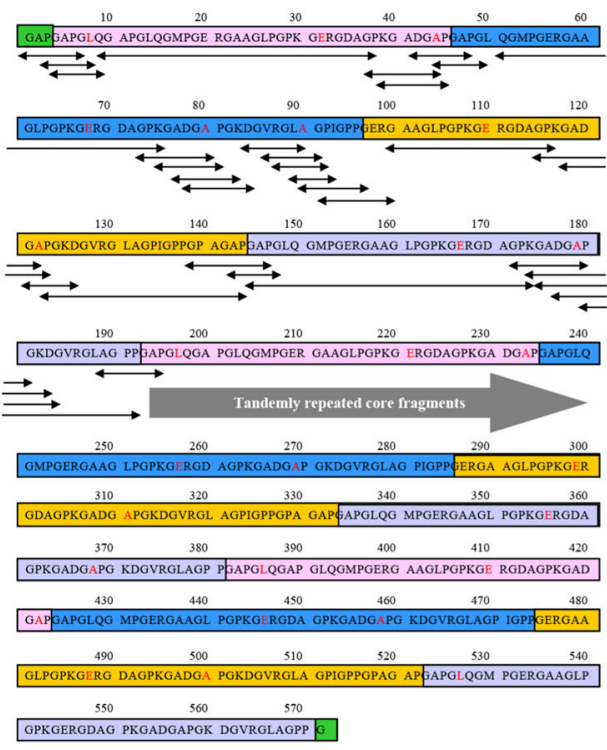

d

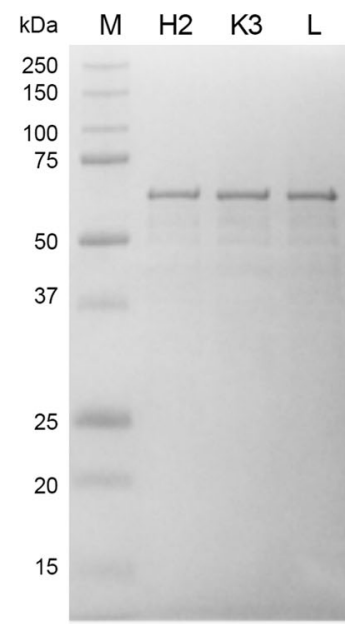

b

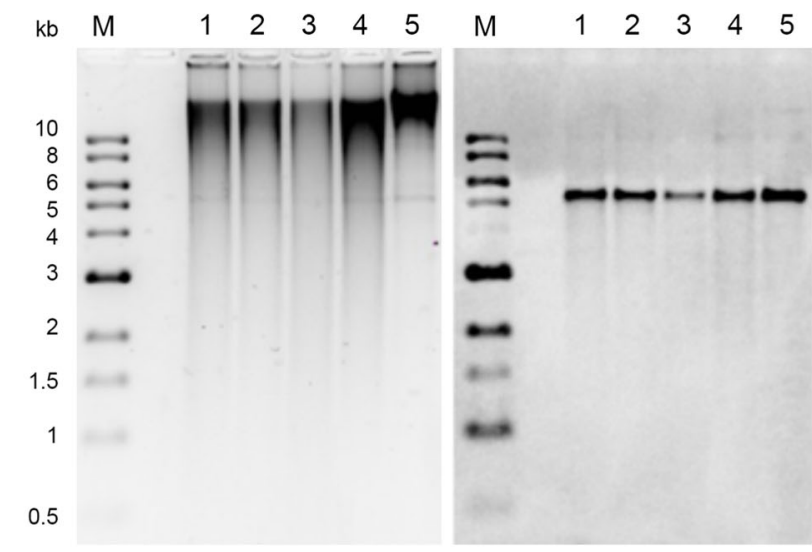

C
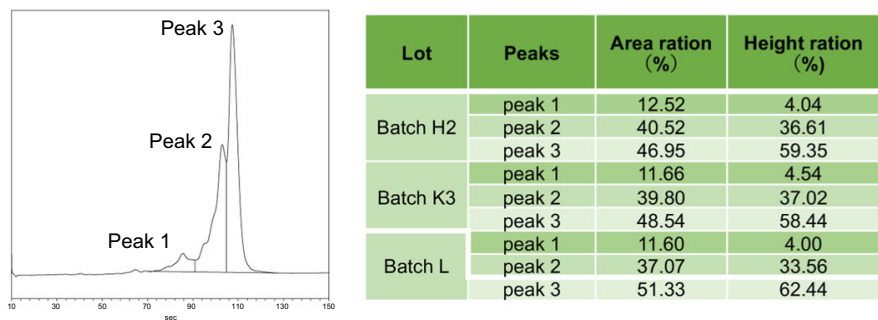

f

\begin{tabular}{|l|c|}
\hline \multicolumn{1}{|c|}{ RCPhC1 } & $\begin{array}{c}\text { Concentration } \\
\text { (ng/mg) }\end{array}$ \\
\hline Rhamnose & N.D. \\
\hline Ribose & N.D. \\
\hline Mannose & <LOQ \\
\hline Fructose & N.D. \\
\hline Galactose & N.D. \\
\hline Xylose & N.D. \\
\hline Glucose & <LOQ \\
\hline Glucosamine & N.D. \\
\hline Galactosamine & N.D. \\
\hline N-glycolylneuraminic acid & N.D. \\
\hline N-acetylneuraminic acid & N.D. \\
\hline
\end{tabular}

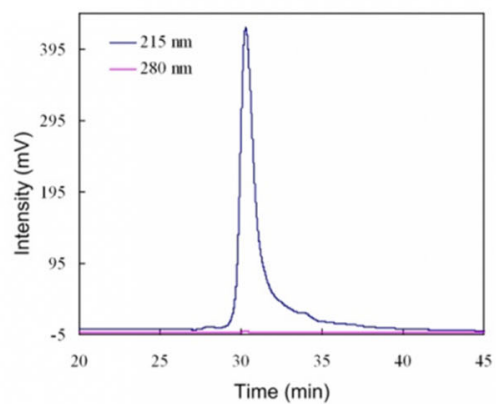

Fig. 1 Molecular design and synthesis of recombinant polypeptide RCPhC1. a The peptide sequence of RCPhC1 shows Gly-Xaa-Yaa repeats with amino acid substitutions (red). All peptide fragments (minimum penta sequences) containing the amino acid substitutions (double head arrows) were matched with human collagen sequences. b Genomic DNA stability in the working cell bank. After each of four consecutive fragmentations, genomic DNA was isolated (lanes 1-4) and compared with the original genomic DNA (lane 5). The right panel, Southern blot hybridized with the AOX1 promoter probe. c Reproducibility was analyzed by liquid chromatography. The reverse-phase profile showed three peaks, which were consistently identified in three different batches $(\mathrm{H} 2, \mathrm{~K} 3$, and $\mathrm{L})$. d Reproducibility was also evaluated by SDA-PAGE. The single band of three different batches also suggested the absence of posttranslational modification. $\mathbf{e}$ The absence of post-translational glycosylation. $\mathbf{f}$ Gel permeation chromatography confirmed the high purity of RCPhC1.

and $\mathrm{RCPhC1}$ sponge was subjected to dehydrothermal crosslinking treatment. Dehydrothermal crosslinked $\mathrm{RCPhC1}$ sponge was first tested by acid decomposition to evaluate the effect of crosslinking temperature and crosslinking duration (Fig. 3a). The result suggested that the crosslinking degree was not significantly affected by crosslinking temperature when it was above $120^{\circ} \mathrm{C}$ (Fig. 3b). Considering the sterilization of downstream $\mathrm{RCPhCl}$ product, the crosslinking temperature was set at $130^{\circ} \mathrm{C}$. The downstream product was tested for microbial contamination and this temperature was shown to be effective for dry heat sterilization in the manufacturing process (data not shown).

By contrast, the crosslinking duration was linearly associated with the crosslinking degree of $\mathrm{RCPhC1}$ up to $10 \mathrm{~h}$ (Fig. 3c). We compared the dehydrothermal crosslinking profiles of $\mathrm{RCPhC1}$ and commercially available porcine gelatin material. While the crosslinking rate of $\mathrm{RCPhCl}$ rapidly increased as demonstrated by increasing survival rate of acid decomposition treatment, porcine gelatin material exhibited a significantly slow crosslinking profile (Fig. 3c). Porcine gelatin material required $72 \mathrm{~h}$ of heat treatment in order to achieve similar physical characteristics as $\mathrm{RCPhC1}$ after $7 \mathrm{~h}$ of dehydrothermal crosslinking (Fig. 3d). However, the dehydrothermal crosslinked porcine gelatin material was mechanically weaker than similarly dehydrothermal crosslinked $\mathrm{RCPhC1}$ (Fig. 3e).

We postulated that the unique amino acid composition of RCPhC1 including the increased number of crosslink sites (Table 1) contributed to its robust dehydrothermal crosslinking 
a

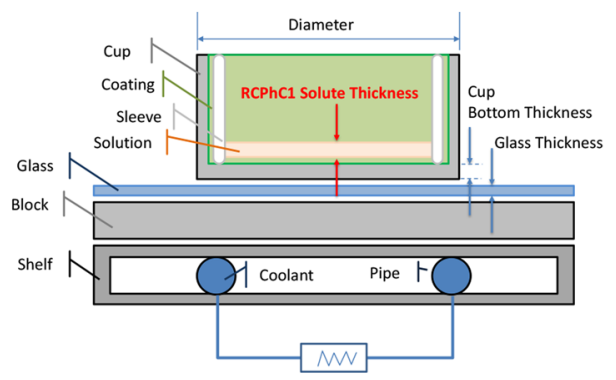

b

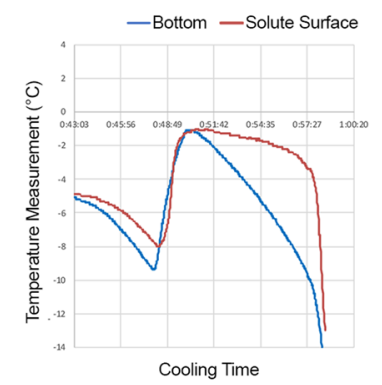

C

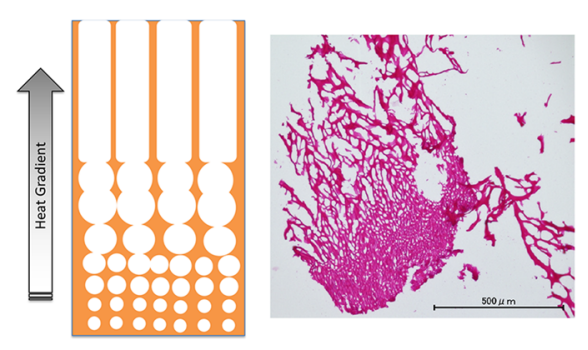

d
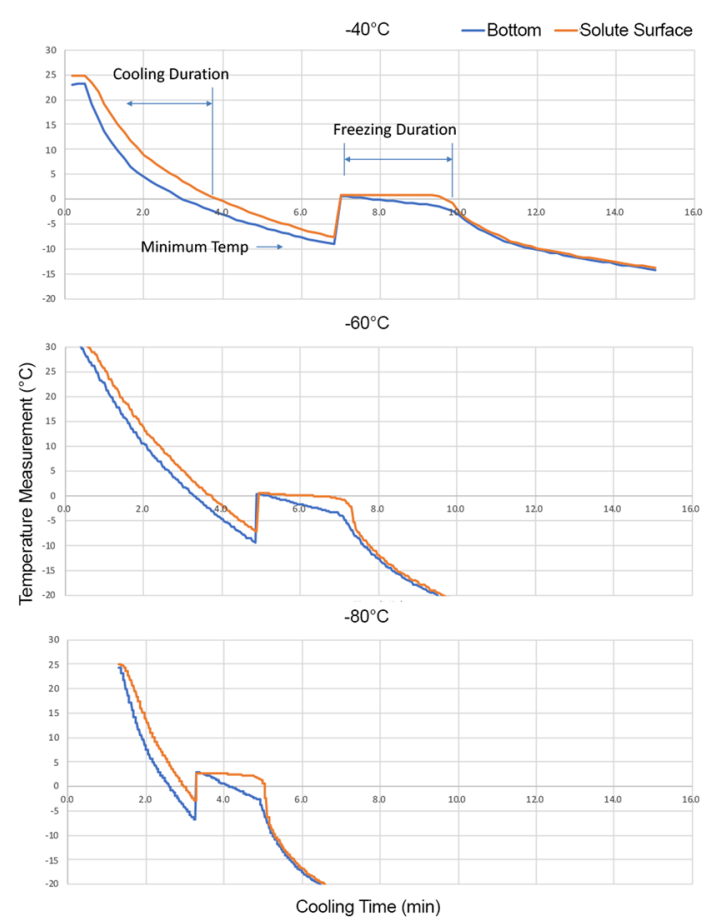

f
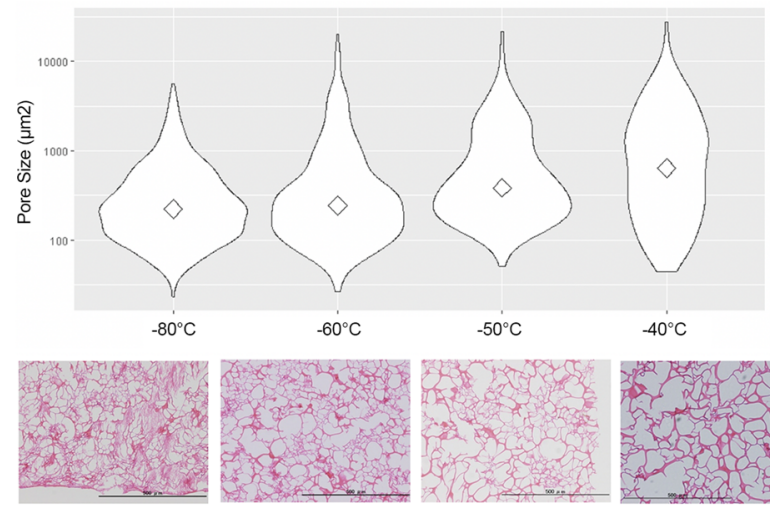

e
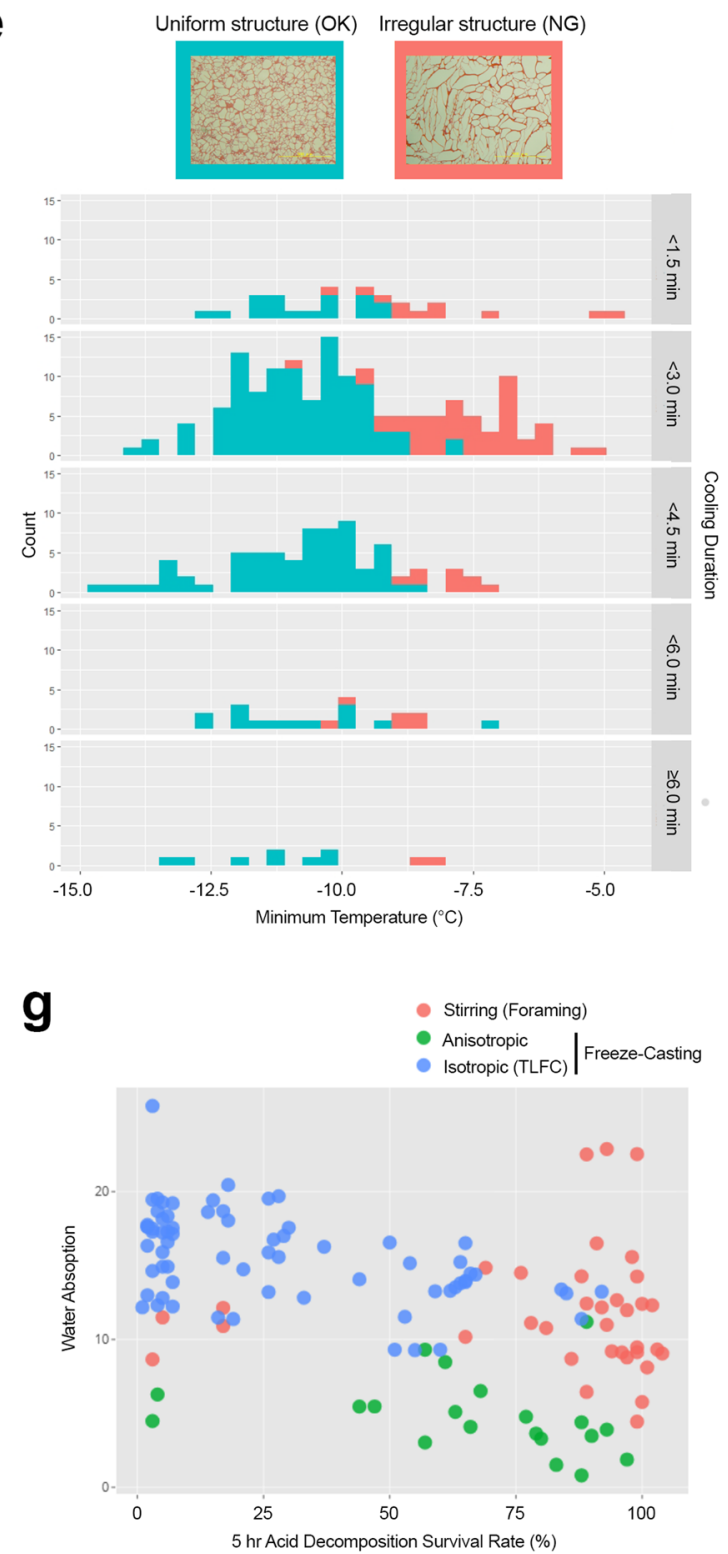

efficiency. The crosslinked $\mathrm{RCPhC} 1\left(130^{\circ} \mathrm{C}\right.$ for $\left.7 \mathrm{~h}\right)$ was treated with trypsin and subjected to liquid chromatography-mass spectrometry (LC-MS). The peptide sequences of trypsindigested dehydrothermal crosslinked RCPhC1 (Fig. 3f) were consistent with those of untreated RCPhC1 (Supplementary Table 2) suggesting that the amino acid content of RCPhC1 was not altered during dehydrothermal crosslinking process. Peptide fragments of RCPhCl containing Asp and Glu were co-recognized with peptide fragments containing Lys (Fig. 3f), supporting our hypothesis and further suggesting that the crosslinking took place at multiple sites in a single molecule. The significantly less effective dehydrothermal crosslinking profile of porcine gelatin material was not explained only by the amino acid composition. We speculate that the uniformity of $\mathrm{RCPhC1}$ may also play an important role in its effective dehydrothermal crosslinking profile. 
Fig. 2 Engineering control factors to develop isotropic ice-templated structures by thin-layer freeze casting (TLFC). a Diagram of freeze casting apparatus. b Typical temperature measurement of the bottom of the cooling cup (blue) and the solute surface (red) during the freeze casting process. There was a significant discrepancy between the cooling cup and the solute surface during the freezing period. c Diagram of anisotropic ice-templated structure and the actual $\mathrm{RCPhC1}$ microstructure containing the small pore zone. Scale bar equals $500 \mu \mathrm{m}$. $\mathbf{d}$ TLFC reduced the temperature discrepancy between the cooling cup (blue) and the solute surface (red) during the freezing period. e The effect of minimum temperature and cooling duration on the isotropic internal pore structure. The uniform pore structure (blue) developed when the minimum temperature was below $-10^{\circ} \mathrm{C}$, but was not affected by the duration of cooling. The irregular internal pore structure (red) more frequently developed when the minimum temperature was above $-10{ }^{\circ} \mathrm{C}$. Scale bar equals $500 \mu \mathrm{m}$. Green area shows the counts of uniformly freeze-dried cakes. Red area shows the counts of irregularly freeze-dried cakes. $\mathbf{f}$ The effect of the block temperature on the internal pore size. Diamonds show median values. The lower block temperatures increased the number of small pores. Scale bar equals $500 \mu \mathrm{m} . \mathbf{g}$ The internal structure developed by the stirring (red circles), anisotropic (green circles) and isotropic (blue circles) freeze casting methods was evaluated by water absorption and acid decomposition analyses. $\mathrm{RCPhC1}$ sponges were tentatively dehydrothermal crosslinked at $130{ }^{\circ} \mathrm{C}$ for $7 \mathrm{~h}$. Blue lines in panels $\mathbf{b}$ and $\mathbf{d}$ indicate the temperature record from the thermocouple at the bottom of the solutions. Red lines indicate that at the surface of the solution.

a

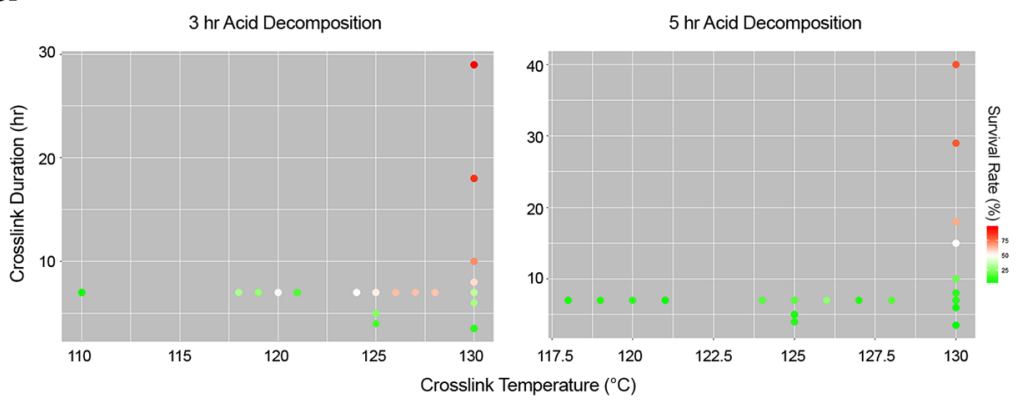

C

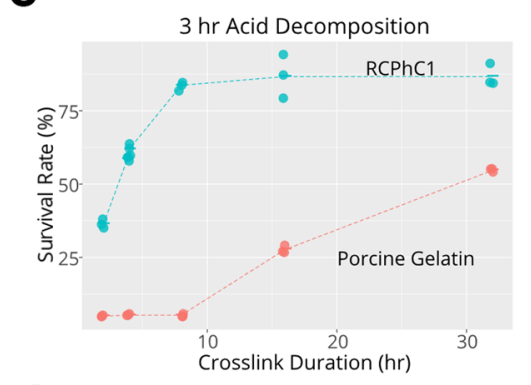

d

\begin{tabular}{|c|c|c|c|c|c|}
\hline \multicolumn{2}{|c|}{ Characterizations } & \multicolumn{3}{|c|}{$\mathrm{RCPhC1}$} & $\begin{array}{l}\text { Porcine } \\
\text { Gelatin }\end{array}$ \\
\hline \multirow{2}{*}{ Heat Crosslinking } & Duration (hr) & 3 & 7 & 18 & 72 \\
\hline & Atmosphare & $\mathrm{N}$ & $\mathrm{N}$ & $\mathrm{N}$ & $\mathrm{N}$ \\
\hline \multicolumn{2}{|c|}{ Crosslinking Sites } & 2.7 & 3.4 & 4.8 & 3.6 \\
\hline \multirow{3}{*}{$\begin{array}{l}\text { Acid Decomposition } \\
\text { (\%) }\end{array}$} & $3 \mathrm{hr}$ & 8 & 59 & 84 & 54 \\
\hline & $5 \mathrm{hr}$ & 2 & 3 & 54 & 12 \\
\hline & $7 \mathrm{hr}$ & 3 & 3 & 27 & - \\
\hline \multicolumn{2}{|c|}{ Water Absorption (\%) } & 1775 & 1463 & 1516 & 1208 \\
\hline
\end{tabular}

e

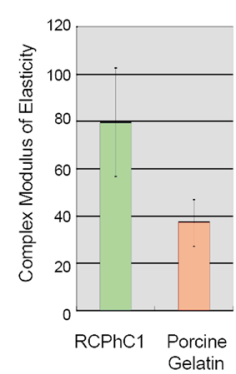

f b

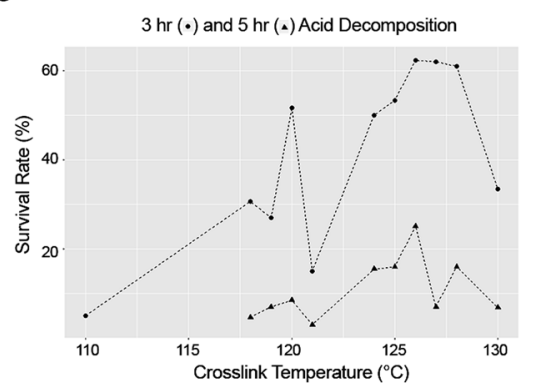

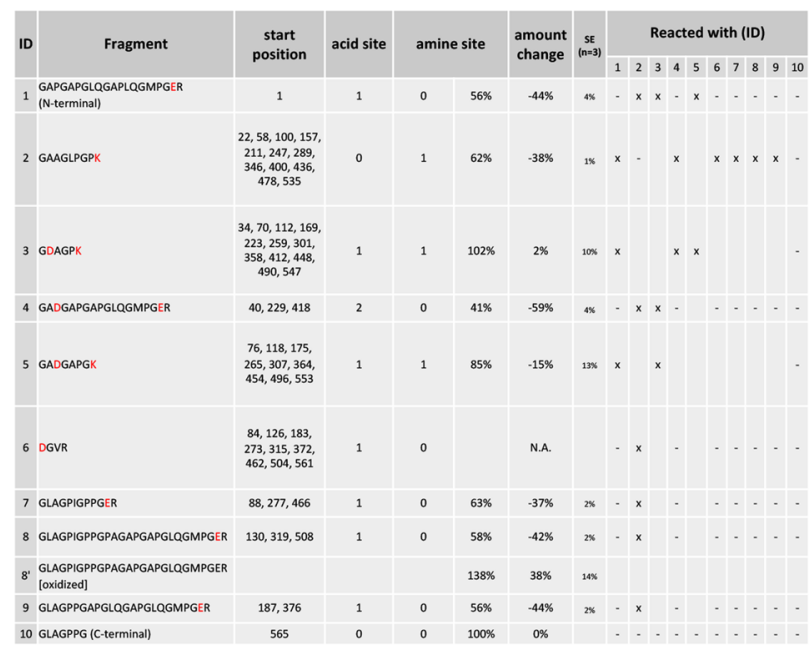

Fig. 3 Engineering factors affecting dehydrothermal crosslinking of RCPhC1 to control biodegradation rate and mechanical strength. a The effect of crosslinking temperature and crosslinking duration on biodegradation rate evaluated by in vitro acid decomposition analysis. $\mathbf{b}$ Crosslinking temperature did not linearly influence the acid decomposition survival rate. Considering the downstream sterilization, the crosslinking temperature was set at $130{ }^{\circ} \mathrm{C}$. c Crosslinking duration was found to be the predominant control factor, which linearly increased the acid decomposition survival rate of RCPhC1 up to $10 \mathrm{~h}$. Porcine gelatin material responded similarly to the crosslinking duration, albeit requiring a much longer duration. $\mathbf{d}$ Physical property of dehydrothermal crosslinked $\mathrm{RCPhC1}$. The equivalent physical property of dehydrothermal crosslinked porcine gelatin required 10 times longer crosslinking duration. e The mechanical strength of dehydrothermal crosslinked $\mathrm{RCPhC1}\left(130^{\circ} \mathrm{C}, 7 \mathrm{~h}\right)$ was significantly higher than that of dehydrothermal crosslinked porcine gelatin $\left(130^{\circ} \mathrm{C}, 72 \mathrm{~h}\right)$. Error bar represents s.d. f Dehydrothermal crosslinked $\mathrm{RCPhC1}\left(130{ }^{\circ} \mathrm{C}, 7 \mathrm{~h}\right)$ was treated with trypsin and subjected to high-performance LC. Co-migration of peptide fragments indicated multiple crosslinking sites.

Optimization of engineering controls for rapid bone regeneration: $\mathrm{RCPhC1}$ concentration, freezing temperature and crosslinking temperature. Next, we optimized the RCPhC1 material for bone grafting. Hydrogel concentrations can modulate the viscosity of the solute affecting the ice-template structure ${ }^{32,47}$. The optimal ranges of $\mathrm{RCPhCl}$ concentration and TLFC freeze temperature were determined by the volume of graft-induced bone in the rat calvarial bone defect (Fig. 4a). The dehydrothermal crosslinking condition was tentatively set at $130{ }^{\circ} \mathrm{C}$ for $7 \mathrm{~h}$. Micro computed tomography (microCT)-based bone volume over total volume (BV/TV) measured at 4 weeks after grafting indicated that the range of $\mathrm{RCPhC1}$ concentration of $7.5-9 \%$, and range of freezing temperature of -40 to $-60{ }^{\circ} \mathrm{C}$ appeared to be the optimal conditions (Fig. 4b). Further 
a

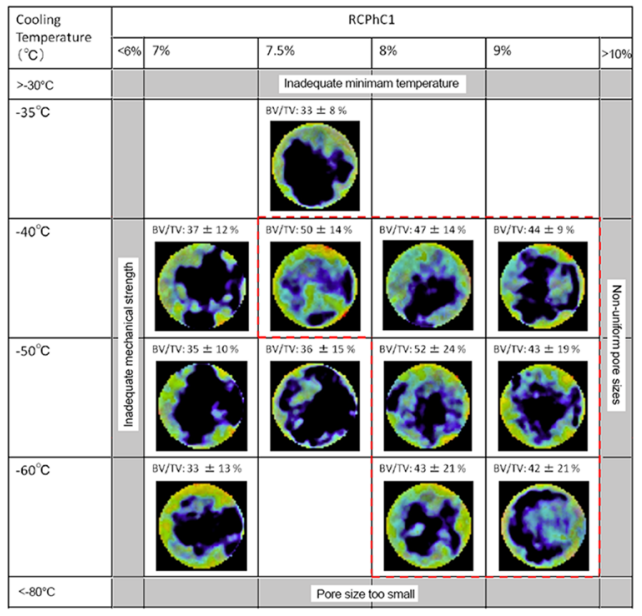

C

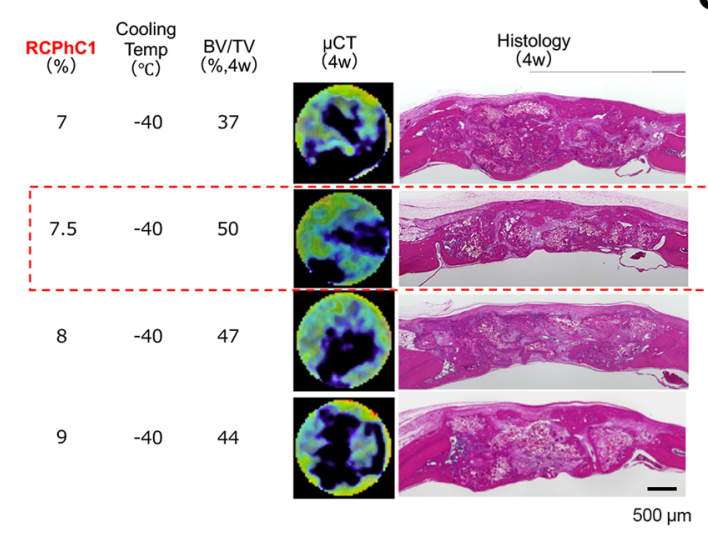

e

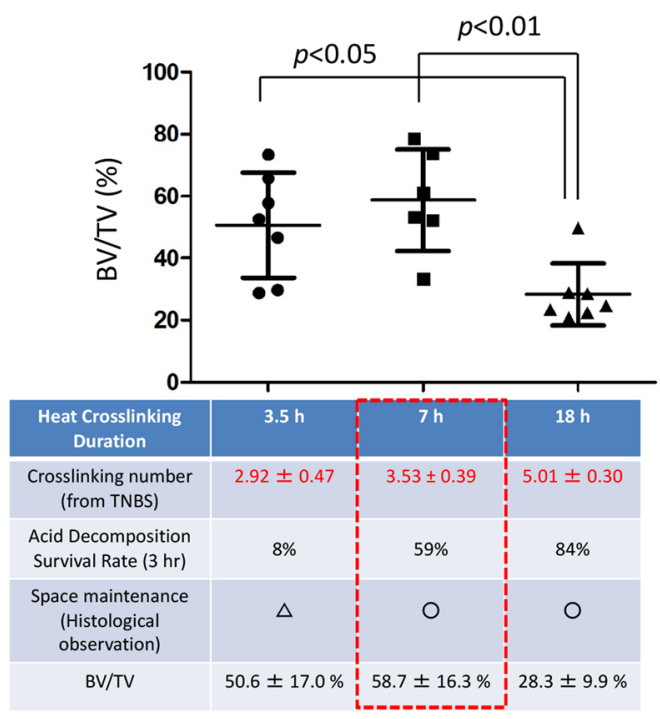

characterization revealed that $\mathrm{RCPhC1}$ concentration of $7.5 \%$ (Fig. 4c) and cooling temperature of $-40{ }^{\circ} \mathrm{C}$ (Fig. 4d) yielded the best $\mathrm{BV} / \mathrm{TV}$ value.

In addition, the dehydrothermal crosslinking duration was optimized. The BV/TV value was significantly decreased when $\mathrm{RCPhC1}\left(7.5 \% ;-40{ }^{\circ} \mathrm{C}\right)$ was treated at $130{ }^{\circ} \mathrm{C}$ for $18 \mathrm{~h}$ as compared to $3.5 \mathrm{~h}$ and $7 \mathrm{~h}$ treatments (Fig. $4 \mathrm{e}$ ). The RCPhC1 b

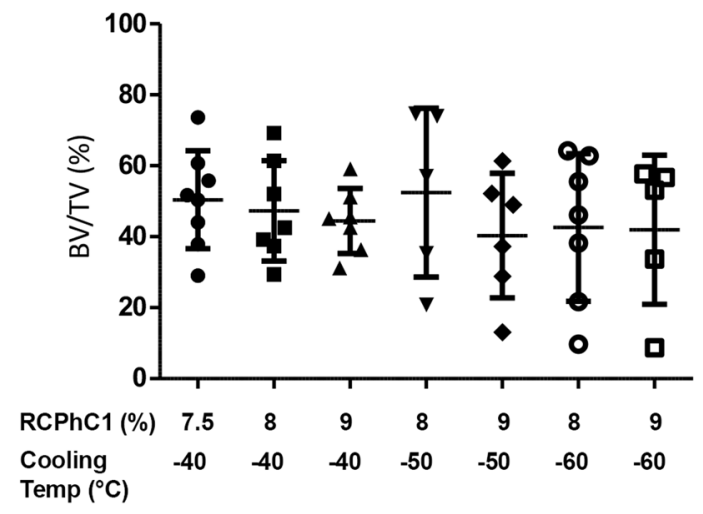

d

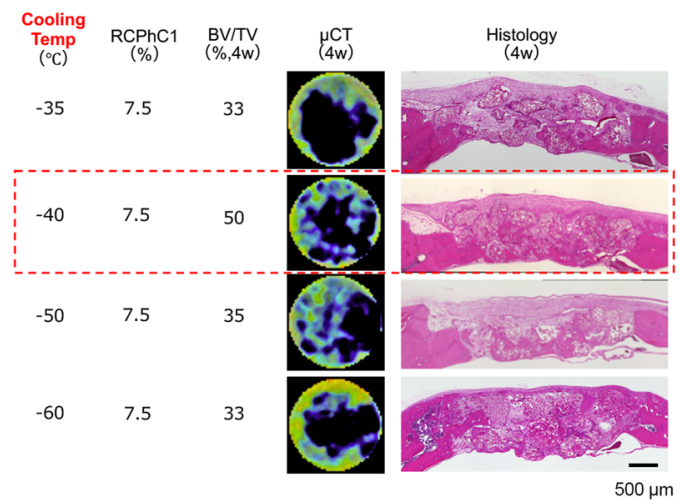

f

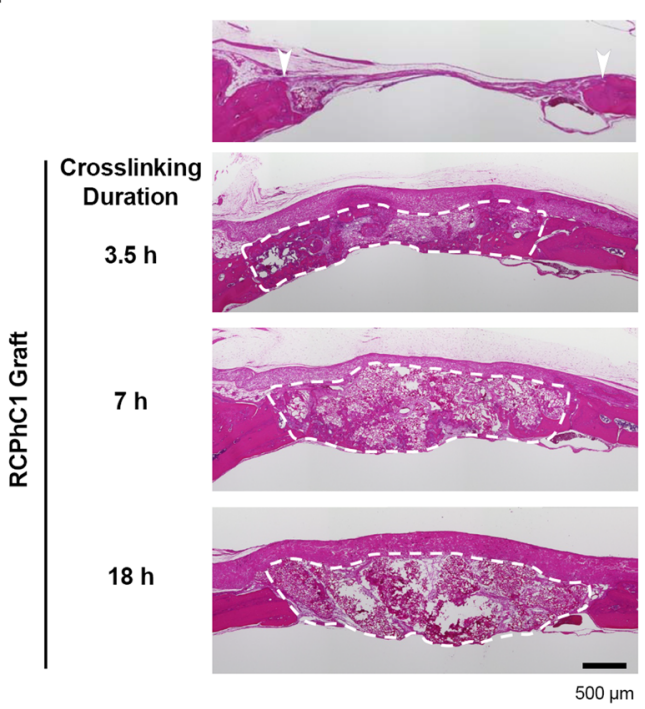

product of the $18 \mathrm{~h}$ protocol largely remained unresorbed in the calvarial bone defect, which seemed to prevent the regeneration of new bone. Furthermore, histological evaluation indicated that $\mathrm{RCPhC1}$ graft with heat duration of $3.5 \mathrm{~h}$ did not resist wound compression (Fig. 4f), suggesting that this condition did not produce the necessary mechanical property of the $\mathrm{RCPhC1}$ graft. Taken together, the optimum conditions for manufacturing 
Fig. 4 Optimization of engineering control factors. a Optimization of combined factors of RCPhC1 solute concentration and TLFC block temperature, with the tentative dehydrothermal crosslinking at $130^{\circ} \mathrm{C}$ for $7 \mathrm{~h}$. The optimal range was narrowed down to $\mathrm{RCPhC1}$ concentration between 7.5 and $9 \%$ and TLFC block temperature between -40 and $-60^{\circ} \mathrm{C}$ (red dotted block). b BV/TV measurements within the group of the optimal range of RCP1C1 concentration and cooling temperature. There was no statistical difference among groups. c The effect of RCPhC1 solute concentration on bone regeneration. Scale bar equals $500 \mu \mathrm{m}$. d The effect of TLFC block temperature on bone regeneration. Scale bar equals $500 \mu \mathrm{m}$. e The effect of dehydrothermal crosslinking duration on bone formation. ( $n=7$; Tukey's multiple comparison test) ( $\mathbf{f}$ ). The effect of dehydrothermal crosslinking duration on the maintenance of wound healing space in the rat calvarial bone defect. White arrowheads show defect edges. White dotted lines circle newly formed tissue. Scale bar equals $500 \mu \mathrm{m}$. Horizontal lines in $\mathbf{b}$, and $\mathbf{e}$ represents mean \pm s.d.

RCPhC1 bone graft were solute concentration of $7.5 \%$, TLFC at $-40^{\circ} \mathrm{C}$, and dehydrothermal crosslinking at $130^{\circ} \mathrm{C}$ for $7 \mathrm{~h}$.

\section{RCPhC1 bone graft induced robust regeneration of vital bone} tissue in preclinical rodent and canine models. $\mathrm{RCPhC1}$ was synthesized in a GMP facility, then freeze-dried in a quality system regulation (QSR) facility. Finally, RCPhC1 bone graft was manufactured in a separate QSR facility using the optimal conditions (Fig. 5a). The RCPhC1 bone graft was porous granules with the size of $300-1200 \mu \mathrm{m}$ (Fig. 5b). In the rat calvarial bone defect, $\mathrm{RCPhC1}$ bone graft robustly induced bone regeneration within the internal pore structure, while gradually degrading (Fig. 5c, Supplementary Fig. 4). The physical structure and granule size of $\mathrm{RCPhCl}$ bone graft were similar to those of a commercially available bovine decellularized cancellous bone xenograft. When bovine xenograft was implanted in the rat calvarial bone defect, no significant bone regeneration measured by microCT (BV/TV) was found (Fig. 5d). Bovine xenograft was integrated with the peripheral bone tissue of the defect; however, xenograft granules were surrounded by fibrous tissue in the center of the defect (Fig. 5e).

$\mathrm{RCPhC1}$ bone graft was evaluated in a canine preclinical model of tooth extraction. Similar to humans, the canine tooth extraction socket undergoes a series of wound healing processes inducing intramembranous bone formation primarily limited to the internal surface of the bone socket, while the external surface of alveolar bone is subjected to significant bone resorption, causing serious problems for dental patients ${ }^{48}$. It has been postulated that increased bone regeneration in the extraction socket should preserve the alveolar bone ${ }^{49}$. The canine tooth extraction socket has provided an ideal model to investigate the effectiveness of bone graft materials such as autograft ${ }^{50}$, decellularized allograft ${ }^{51}$, bovine decellularized xenograft ${ }^{52}$, and synthetic bone graft $^{53}$. Using a published protocol ${ }^{54}$, a canine mandibular third premolar was hemisected and the distal root was extracted. The remaining mesial root was endodontically treated and served as a reference to determine the extraction socket (Fig. 5f). The extraction socket that received RCPhC1 bone graft showed increased bone formation at 12 weeks (Fig. $5 \mathrm{~g}, \mathrm{~h}$. The 95\% confidence interval was 1.25-13.80; degree of freedom was 7; and $p$ value was 0.025 .). After 4 weeks of $\mathrm{RCPhC1}$ bone graft implantation, active bone regeneration was observed in the pore structure (Fig. 5i, Supplementary Fig. 5). RCPhC1 appeared to be degraded or integrated in the newly formed bone (Fig. 5i). After 12 weeks, RCPhC1 bone graft was largely replaced by bone tissue. RCPhC1-induced bone contained a large number of osteocytes and the bone marrow was highly vascularized (Fig. 5i). These rodent and canine preclinical studies demonstrated that $\mathrm{RCPhC1}$ bone graft induced robust bone regeneration activity.

The safety of RCPhC1 bone graft was evaluated in a separate canine experiment, in which one group received $\mathrm{RCPhC1}$ bone graft in the tooth extraction socket and other animals served as the empty control group. The histopathological report on inflammatory cell infiltration in the cervical lymph nodes downstream of the mandibular extraction socket (Supplementary Table 6) as well as peripheral blood panel (Supplementary Table 7) and blood chemistry (Supplementary Table 8) together indicated no pathological changes caused by the implantation of $\mathrm{RCPhC1}$ bone graft.

\section{Discussion}

Type I collagen is the most abundant protein in vertebrate animals, maintaining the structural integrity of bone, skin and surrounding connective tissue. During wound healing, collagen scaffolds support cell proliferation and migration, which are critical for the sound reorganization of lost tissue and functional recovery. In recent decades, collagen-based hydrogels have been extensively investigated for biological tissue substitutes and scaffold biomaterials for tissue engineering ${ }^{55}$. Animal-derived collagen extracts have been the primary source of hydrogel materials in the medical field ${ }^{56}$ as well as in the food and cosmetic industries ${ }^{57}$. However, the development of collagen-based biomaterials as an implantable medical device has been challenging.

The limitation of animal collagen extracts is primarily due to the lack of homogeneity of collagen fragments and the limited engineering flexibility. Therefore, we designed and successfully synthesized the recombinant collagen monomeric polypeptide based on human type I collagen alpha 1 chain (RCPhC1) (Fig. 1). Due to its amino acid substitutions and inherent homogeneity, $\mathrm{RCPhC1}$ was found to be a versatile source for manufacturing implantable biomaterial scaffold with the desired specifications (Figs. 2 and 3). RCPhC1 was previously commercialized as a research reagent "RCP" in $4 \%$ solution or lyophilized powder (Cellnest ${ }^{\mathrm{TM}}$, FUJIFILM Manufacturing Europe BV). Although the marketing of Cellnest ${ }^{\mathrm{TM}}$ has been discontinued, the RCP reagent supported a range of investigations such as bioinspired mineralization ${ }^{27,33}$ and scaffold carrier of stem cells ${ }^{58,59}$. The aim of the present manuscript is to describe the detailed information of $\mathrm{RCPhC1}$ and the newly developed downstream engineering processes leading to the bone graft material.

We optimized the simple but critical engineering control factors of the solute concentration of RCPhC1, TLFC freezing temperature and dehydrothermal crosslinking duration. Instead of relying on in vitro assays, our project systematically applied the in vivo rat calvarial bone defect model to determine the optimal engineering factors to manufacture RCPhC1 bone graft (Fig. 4). The rat calvarial bone defect has been extensively utilized to measure graft-induced bone formation. Bone marrow mesenchymal stem cells (MSC) are primarily responsible for regenerating bone tissue in large defects. Bone graft materials are designed to support MSC's migration toward the defect area and provide a microenvironment that stimulates their osteogenic differentiation. However, this critical biological event has rarely been achieved by allogeneic and synthetic graft materials. Therefore, combined biologic graft products containing recombinant growth factors were developed and tested in the rat calvarial bone defect model $^{60-62}$. Recently, this model was also used to evaluate the effect of engineered stem cell grafting ${ }^{63-66}$. In the present study we demonstrated that optimization of $\mathrm{RCPhC1}$ graft materials 
a
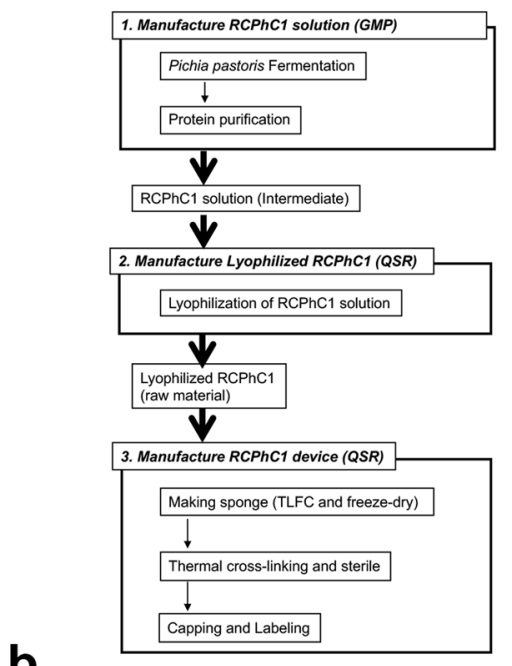

b
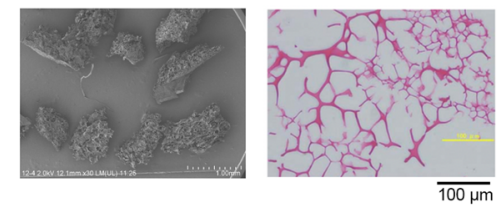

f
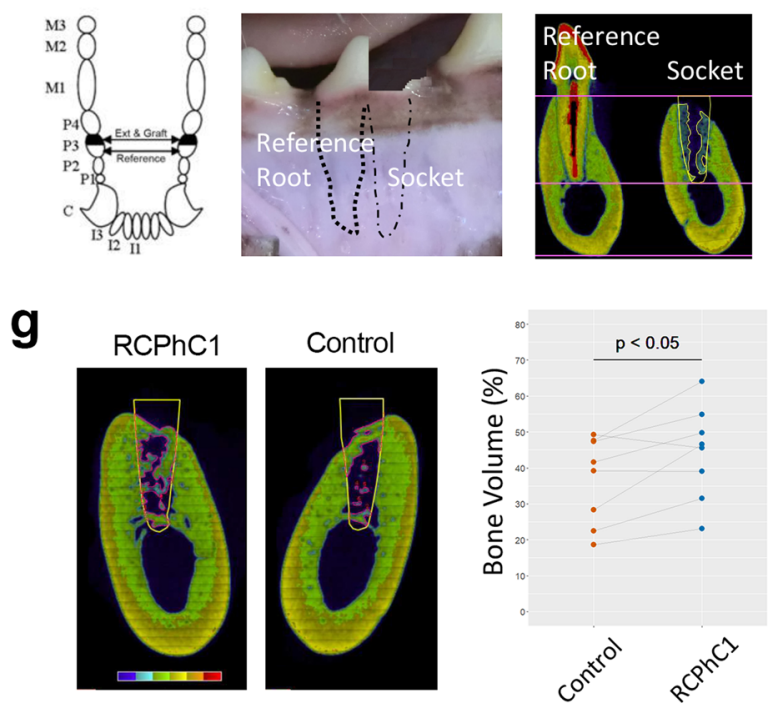

h
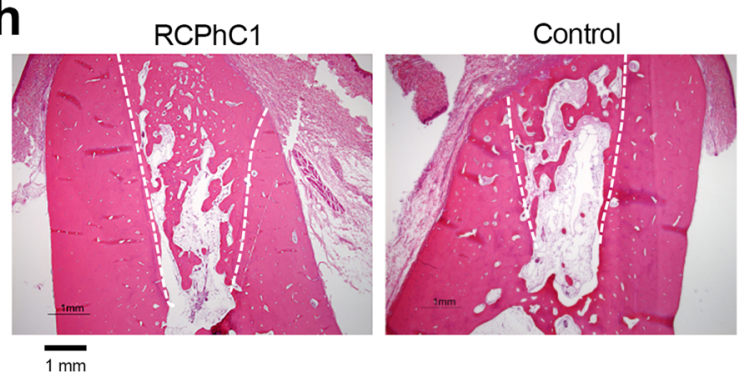

resulted in bone regeneration in the rat calvarial bone defect without combining biologic components such as growth factors and stem cells (Fig. 4, Fig. 5c). RCPhC1 bone graft exhibited an ideal healing pattern of integration in the regenerating bone. By contrast, decellularized bone xenograft was found to induce fibrosis tissue, preventing the necessary bone regeneration (Fig. 5d, e).

C
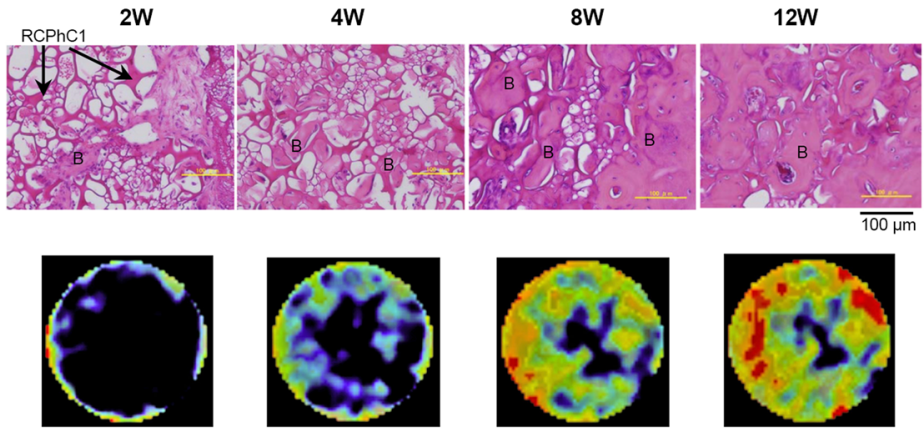

e
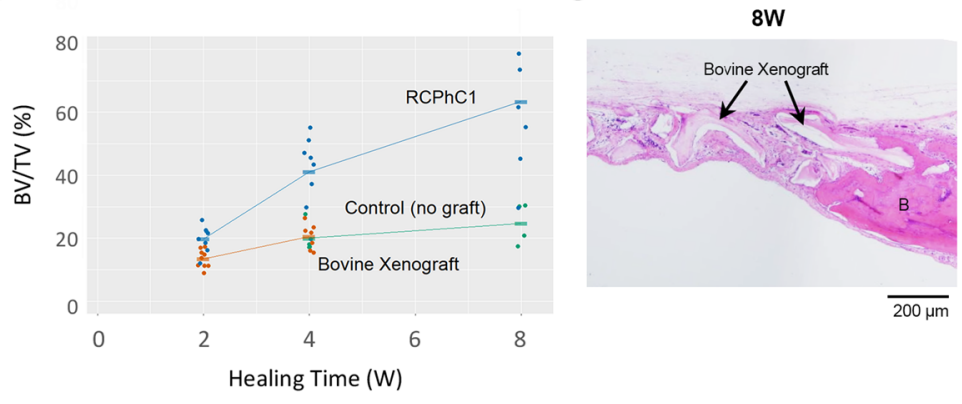

$4 \mathrm{~W}$

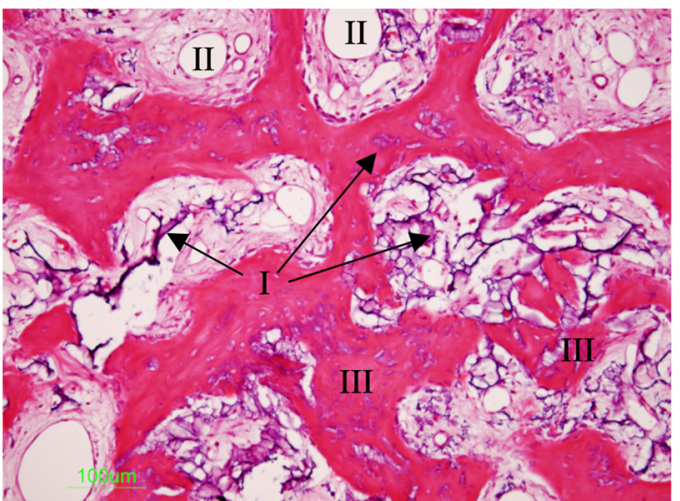

$12 \mathrm{~W}$

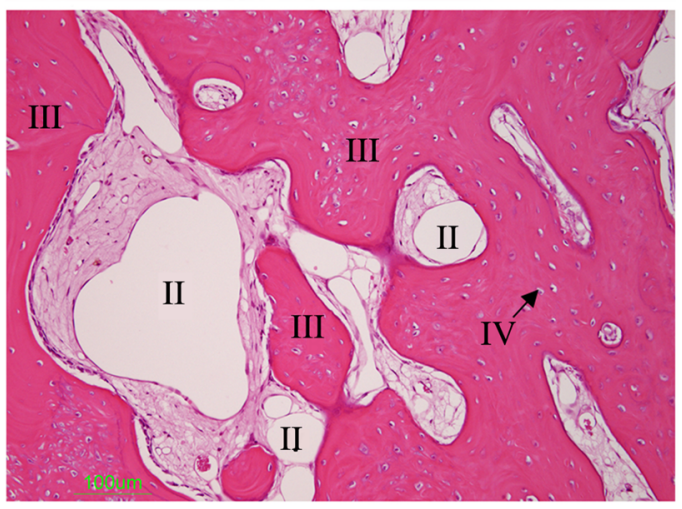

$100 \mu \mathrm{m}$

Regulatory approval of medical devices by the Food and Drug Administration (FDA) generally requires evidence of efficacy and safety in rodents as well as non-rodent preclinical animal models. The purpose of using non-rodents is usually for confirmatory experiments to facilitate extrapolation of the experimental results to humans ${ }^{67}$. The preclinical canine model has been widely used for bone graft materials ${ }^{68}$, particularly dental bone grafts ${ }^{53,69-71}$. 
Fig. 5 Preclinical efficacy test of the RCPhC1 material optimized for bone graft in rodent and canine models. a Flow chart of the RCPhC1 bone graft manufacturing process. Scale bar equals $100 \mu \mathrm{m}$. b RCPhC1 bone graft was prepared as porous granules of size 300-1200 $\mu \mathrm{m}$ for better handling. Scale bar equals $100 \mu \mathrm{m}$. c Time course of bone regeneration induced by RCPhC1 bone graft in the rat calvarial defect model. Histological analysis (top row) revealed newly formed bone tissue (B) within RCPhC1 graft material, which was resorbed over time (see Supplementary Fig. 4). A time course series of in vivo microCT (bottom row) depicted the progressive increase in bone tissue. $\mathbf{d}$ Time course of BV/TV measurement of rat calvarial bone defect implanted with $\mathrm{RCPhC1}$ bone graft, bovine decellularized cancellous bone xenograft and no graft control. e Histological evaluation of bovine xenograft implanted in rat calvarial bone defect. The physical structure of bovine xenograft was similar to that of RCPhC1 bone graft. At the periphery of the defect, bovine xenograft was seen fused to the newly formed bone (B). In the center of the defect, bovine xenograft granules were surrounded by fibrous tissue. Scale bar equals $200 \mu \mathrm{m}$. f Canine tooth extraction model. The canine third premolar (P3) has nearly identical mesial and distal roots. The third premolar was hemisectioned and only the distal root was extracted. One side of the post-extraction bony socket was filled with RCPhC1 while the other side was left to heal without any further treatment. The remaining medial root was endodontically treated and served as a reference. Scale bar equals 4 mm. $\mathbf{g}$ MicroCT crosssection depicting bone regeneration in the extraction socket (white line) after 12 weeks ( $12 \mathrm{~W}$ ) of healing. The bone volume within the socket was significantly larger in the RCPhC1 bone graft implanted socket than the untreated control socket ( $n=8$; two-sided paired $t$-test). Scale bar equals 4 mm. $\mathbf{h}$ Histological cross section of the extraction socket (white line) at $12 \mathrm{~W}$. The socket that received $\mathrm{RCPhC1}$ bone graft exhibited larger bone regeneration. Dotted white lines show socket interfaces. Scale bar equals $1 \mathrm{~mm}$. i Histological evaluation of RCPhC1 bone graft (I) associated bone regeneration. Abundant vascular formation (II) in the bone marrow tissue was noted of regenerating bone (III) after 4 weeks ( $4 \mathrm{~W}$ ) of healing. RCPhC1 bone graft was largely resorbed after $12 \mathrm{~W}$ of healing. The regenerated bone contained vital osteocytes (IV).

Tooth extraction is the final treatment for dental caries, periodontitis and injury. According to the database of the Center of Disease Control and Prevention, among adults in the US aged $20-64$, the prevalence of loss of at least one tooth is over $50 \%$, increasing to over 75\% in those aged 40-64 (https://www.cdc.gov/ nchs/products/databriefs/db197.htm), and even higher in adults aged 65 and over; $27.27 \%$ of seniors have no remaining teeth (https://www.nidcr.nih.gov/research/data-statistics/tooth-loss/ seniors). Dental bone graft has been shown to mitigate the posttooth extraction loss of jawbone ${ }^{72}$. The present study demonstrated the effectiveness of $\mathrm{RCPhC1}$ bone graft in inducing bone regeneration in the canine tooth extraction socket while being resorbed (Fig. 5).

In conclusion, the recombinant polypeptide of human type I collagen alpha 1 chain with targeted amino acid substitutions (RCPhC1) was demonstrated to be a source material for generating tissue-specific medical devices and graft scaffolds. $\mathrm{RCPhC1}$ not only inherently lacks animal- and cadaver-derived infectious and disease pathogens but also provides significant manufacturing versatility to precisely optimize the downstream medical device configuration. RCPhC1 bone graft produced through highly scalable processes exhibited robust bone regeneration in rodent and canine preclinical models without the use of biologics and cellular combinatory products.

\section{Methods}

RCPhC1 synthesis and quality control. $\mathrm{RCPhC1}$ was produced in the yeast Pichia pastoris, using methods described in a patent, WO2008103041. Briefly, RCPhC1 was manufactured using recombinant technology and expressed by Pichia pastoris. The protein sequence of $\mathrm{RCPhCl}$ is composed of three units of the following four sequence domains of human type I collagen $\alpha 1$ chain (GenBank accession number P02452 version 4)

Fragment 1: amino acids 716 up to and including 757 of GenBank P02452

Fragment 2: amino acids 722 up to and including 772 of GenBank P02452

Fragment 3: amino acids 731 up to and including 778 of GenBank P02452

Fragment 4: amino acids 722 up to and including 769 of GenBank P02452

This RCPhC1 sequence was designed to prevent genetic instability during the repeated fermentations. Further sequence substitutions were made. Serine (S) and threonine $(\mathrm{T})$ residues that could provide potential glycosylation sites for the host strain Pichia pastoris, were substituted by either (leucine) L or (alanine) A as follows: S8 $\rightarrow$ L; S44 $\rightarrow$ A; S80 $\rightarrow$ A; T90 $\rightarrow$ A; S122 $\rightarrow$ A; T132 $\rightarrow$ A; S179 $\rightarrow$ A; $\mathrm{T} 189 \rightarrow \mathrm{A}$. In addition, the following amino acid substitutions were made to prevent degradation: $\mathrm{D} 32 \rightarrow \mathrm{E} ; \mathrm{D} 68 \rightarrow \mathrm{E} ; \mathrm{D} 110 \rightarrow \mathrm{E} ; \mathrm{D} 167 \rightarrow \mathrm{E}$.

The RCPhC1 cDNA construct was inserted to pPICZa A with AOX1 promoter (Invitrogen) and the resultant expression vector was transformed into Pichia pastoris. The process to manufacture $\mathrm{RCPhC1}$ consisted of fermentation, purification and freeze-drying. During the fermentation process, methanol-induced $A O X 1$ promoter activation resulted in the synthesis of $\mathrm{RCPhC1}$, which was secreted into the medium. The RCPhC1 was recovered by centrifugation and filtration. The purification process consisted of packed-bed cation exchange chromatography followed by ultrafiltration and diafiltration. It was further purified by anion exchange and mixed-mode chromatography to remove any remaining process impurities. The RCPhCl then was concentrated and subjected to a final $0.2 \mu \mathrm{m}$ filtration before it is freeze-dried and packed.

The RCPhC1 has an amino acid sequence of 571 amino acids $(\mathrm{Mw}=51 \mathrm{kDa})$ and a $\mathrm{pI}$ of 10.0. The amino acid composition of $\mathrm{RCPhC1}$ was determined by hydrolysis with hydrochloric acid and subsequent amino acid analysis. We compared the amino acid composition determined by the test with the theoretical amino acid composition. Furthermore, the amino acid composition of commercially available porcine, bovine and marine (fish) collagen/gelatin products was compared. The further characterization of $\mathrm{RCPhC1}$ is described in the text and Supplementary Tables 2-5 and Supplementary Figs. 1 and 2.

Freeze casting and thin-layer freeze casting. Packed freeze-dried $\mathrm{RCPhC1}$ was dissolved in Water for Injection (WFI) at predetermined concentrations (i.e., 7.0, $7.5,8.0$, or $9.0 \mathrm{w} / \mathrm{v} \%)$. The $\mathrm{RCPhC1}$ solution was filtered and subjected to freezedried using a thin-layer freezing method. To test the effect of cooling rate on scaffold structure, RCPhC1 solutions were frozen on a chilled aluminum block a different temperatures. A5056 aluminum blocks $(5 \times 5 \times 2 \mathrm{~cm})$ were cooled in a deep-freezer (RS-U30T, Hitachi Global Life Solutions, Inc., Japan) for more than $2 \mathrm{hr}$. Eight $\mathrm{mL}$ of RCPhC1 solution was poured into a fluorinated-polymer (NF004-A, Nippon Fusso Co., Ltd., Japan) coated A5056 aluminum cup (53(d) $\times$ $38(\mathrm{t}) \mathrm{mm}$ ) with polytetrafluoroethylene circular sleeve ( $3 \mathrm{~mm}$ thickness). One cup was put onto the cooled block to let the solution freeze. The frozen solution was freeze-dried under vacuum at a shelf temperature of $-20^{\circ} \mathrm{C}$ in a freeze-dryer (TF585ATNNN, Takara ATM Co., Ltd., Japan).

To retard freezing, glass plates $(76 \times 52 \times 1 \mathrm{~mm})$ were inserted between the block and the cup. All shown scaffolds were frozen with two plates inserted. When measuring solution temperature, a multichannel thermologger (FUSO-309, Fuso Co., Ltd., Japan) was used with type K thermocouples.

\section{Time course of temperature measurement at the top and bottom of the} container. During freezing, the temperature in the $\mathrm{RCPhC1}$ solution was recorded via two type $\mathrm{K}$ thermocouples. One thermocouple was placed in contact with the bottom of the cup, and the other was held in the solution $1.5 \mathrm{~mm}$ above the bottom. The temperature was recorded every second throughout freezing.

Pore size analytical methods: water absorption, cross section. To determine the average pore size of the scaffolds, thin slices were retrieved from the midline of each RCPhC1 sponge and crosslinked as the same as particles described below. The $\mathrm{RCPhCl}$ crosslinked sponges were embedded in paraffin, sectioned at $5 \mu \mathrm{m}$ thickness, stained using Eosin Y (Muto Pure Chemicals Co., Ltd., Japan), and visualized on an optical microscope (IX81, Olympus Corp., Japan). For each section, three digital images were taken using a charge-coupled device (CCD) color camera (DP70, Olympus Corp., Japan).

Each image was made into two Gaussian mixture models in which the pore and wall probabilities of each pixel were depicted by its brightness value. Based on this initial probability model, an energy function was defined. The graph cut optimization method was used to optimize the energy function. The optimization was repeatedly applied and the model was updated each time. The areas of "pore" region in the optimized model were measured. These areas were taken as pore sizes without correction for cutting position/angle.

Mechanical testing. The freeze-dried $\mathrm{RCPhC1}$ sponges were cut into $10 \times 5 \times$ $2 \mathrm{~mm}$ and crosslinked as described below. After soaking in saline at ambient 
temperature for 4 days, viscoelasticity of the sponges was measured with a mechanical tester (Rheogel-E4000, UBM K.K., Japan). Cycle deformation of $2 \%$ was applied at $10 \mathrm{~Hz}$, and complex moduli of elasticity were recorded.

Preparation of RCPhC1 particles. The freeze-dried $\mathrm{RCPhC1}$ sponges were milled in a blender (New Powermill, Osaka Chemical Co., Ltd., Japan). and sieved with analytical sieves. Particles between $1-\mathrm{mm}$ and $300-\mu \mathrm{m}$ sieves were used in further testing.

Dehydrothermal crosslinking: temperature range. All $\mathrm{RCPhC1}$ particles were first dried under vacuum $(0.2 \mathrm{kPa})$ at a temperature of $90^{\circ} \mathrm{C}$ for $1.5 \mathrm{~h}$. The dried $\mathrm{RCPhC1}$ particles were then dehydrothermally crosslinked in an inert oven (VAC201 P, Espec Corp., Japan) under $\mathrm{N}_{2}$ atmosphere $(101.3 \mathrm{kPa}$ ) at a specified temperature between 110 and $130{ }^{\circ} \mathrm{C}$ and a specified duration from 3 to $40 \mathrm{~h}$. The optimal dehydrothermal crosslink condition was determined by the acid decomposition assay to be $130{ }^{\circ} \mathrm{C}$ for $7 \mathrm{~h}$. In a separate experiment, a porcine gelatin product was dehydrothermally crosslinked up to $72 \mathrm{~h}$.

Quantification of crosslinking number. The amount of crosslinked amines were quantified by reaction with 2,4,6-trinitrobenzensulfonic acid (TNBS). All tests were triplicated, and a blank without sample was prepared. Ten (10) $\mathrm{mg}$ of crosslinked $\mathrm{RCPhC1}$ particles were measured into a $30-\mathrm{mL}$ glass vial. To the tube, $1 \mathrm{~mL}$ of $4 \mathrm{w} \%$ $\mathrm{NaHCO} 3$ aq. and $2 \mathrm{~mL}$ of $1 \mathrm{w} \%$ TNBS aq. were added. The tube was shaken $(60 \mathrm{cpm})$ for $5 \mathrm{~h}$ in an incubator kept $37^{\circ} \mathrm{C}$. After shaking, $10 \mathrm{~mL}$ of conc. hydrochloric acid and $5 \mathrm{~mL}$ of water were added to the tube. The tube kept longer than $16 \mathrm{~h}$ in the incubator until all the particles were dissolved. The dissolved solution was diluted ten times and absorbance at $345 \mathrm{~nm}$ was measured. The absorbance of the blank was subtracted. The amount of free amine (i.e., not crosslinked) was calculated using molar extinction coefficient $\varepsilon=14,200$ (L/ $\mathrm{mol} \bullet \mathrm{cm})$.

Animal ethics. All of the experimental protocols using animals were reviewed and approved by the institutional animal care and use committee of FUJIFILM Corporation. Every experiment was complied with ethical guidelines. All animals had free access to food and water and were maintained in regular animal housing.

Rat calvarial critical size defect and RCPhC1 bone graft implantation. Adult (9-13 week old) male Sprague-Dawley rats were used in this study following the established protocol ${ }^{61}$. The study showed standard deviation smaller than $10 \% \mathrm{BV} /$ TV. To show $15 \%$ BV/TV difference with power 0.8 , and $P<0.05$, power calculation showed sample size must be 8.06 . When the materials did not sit in the defect on harvesting, we excluded the animal, and we used 10 animals for each test. We did not randomize sample allocation. We used animals of specified breeder (Charles River Japan), strain, sex, and age to avoid covariates effects. Investigators were blinded while data collection, and analysis.

Ten (10) animals were used in each test and at each healing duration. Animals were anesthetized by intraperitoneal injection of pentobarbital. The surgical area was shaved, and the skin was washed with an antiseptic solution of iodine and $70 \%$ ethanol. An incision was made along the midline. Full-thickness skin was raised to expose the calvaria. Periosteal tissue over the parietal bone was removed. A calvarial defect of $5 \mathrm{~mm}$ in diameter was made with a trephine drill (Osada Inc., Japan), and cleaned with cotton swabs to remove any bone powder and blood. RCPhC1 graft particles $\left(3.6 \mathrm{mg}\right.$ ) or bovine xenograft particles (Bio-Oss ${ }^{\oplus}$, Geistlich Pharma, Switzerland) mixed with $10 \mu \mathrm{L}$ of saline was uniformly implanted into the bone defect and covered with a collagen membrane (Bio-Gide, Geistlich Pharma, Switzerland). The wounds were sutured after implantation with silk sutures.

MicroCT. R-mCT (Rigaku, Japan) was used to examine bone formation in individual rats. Rats were anesthetized with $2 \%$ isoflurane and in vivo microCT imaging was performed. Voxel size was $100 \mu \mathrm{m}$, X-ray tube potential was $90 \mathrm{kVp}, \mathrm{X}$ ray intensity was $100 \mu \mathrm{A}$, and integration time was $30 \mathrm{~ms}$. Measured density was daily calibrated with a phantom. Image reconstruction and BV/TV measurements were performed using the Tri-3D Bon software (version R.11.00.00.0-H, RATOC System Engineering Co., Ltd., Japan). Cylindrical area $(5 \mathrm{~mm}(\mathrm{~d}) \times 1.2 \mathrm{~mm}(\mathrm{~h}))$ including the defect was defined as tissue volume (TV), and the tissue having density larger than $110 \mathrm{mg} \mathrm{HA} / \mathrm{cm}^{3}$ was regarded as bone. MicroCT imaging was performed at week $2,4,8$, and 12 .

Histology. For histopathological examination, the rat calvaria were harvested and fixed with $4 \%$ paraformaldehyde phosphate buffer solution, embedded in paraffin, and sectioned transversely at $3 \mu \mathrm{m}$ thickness. Each slice was stained with hematoxylin and eosin (H\&E).

Canine tooth extraction and RCPhC1 bone graft implantation. A total of 24 male beagle dogs (14 month old) were used for the experiment. The third premolars (P3) of both sides were used for the experiment following the published experimental protocol ${ }^{50,52,54}$. We did not randomize sample allocation. We used a split mouth method, in which one animal received the test article and control in each side of the jaw. Two days before tooth extraction, the animals were lightly anesthetized with intramuscular injection of medetomidine hydrochloride at 0.05 $\mathrm{mg} / \mathrm{kg}(0.05 \mathrm{~mL} / \mathrm{kg})$ into the thigh muscle, and plaque was removed with a scaler (Suprasson P-Max). After washing the application sites, the animals were awakened from anesthesia by intramuscular injection of atipamezole hydrochloride at $0.25 \mathrm{mg} / \mathrm{kg}(0.05 \mathrm{~mL} / \mathrm{kg})$ into the thigh muscle. Atropine sulfate at $0.05 \mathrm{mg} / \mathrm{kg}$ $(0.1 \mathrm{~mL} / \mathrm{kg})$ was injected subcutaneously into the back of the neck. About 10 to $30 \mathrm{~min}$ after administration of the atropine sulfate injection, sodium thiopental at $25 \mathrm{mg} / \mathrm{mL} / \mathrm{kg}(1 \mathrm{~mL} / \mathrm{kg})$ was injected into the cephalic vein to induce anesthesia. The administration was performed using a disposable polypropylene hypodermic syringe (Terumo Corporation) to which an injection needle (Terumo Corporation) was attached. Then a tracheal cannula (Tracheal Tube, PORTEX) was inserted, and anesthesia was maintained with an anesthesia machine (Vigor 21 DX, Acoma Medical Industry Co., Ltd.) by inhalation of $0.5-1.5 \%$ sevoflurane with a gas mixture of $\mathrm{N}_{2} \mathrm{O}$ and $\mathrm{O}_{2}$ at a ratio of 1:1 under respiratory conditions at $10-15 \mathrm{~mL} / \mathrm{kg}, 18-22$ times/minute using an artificial respirator (ACE-3000, Acoma Medical Industry Co., Ltd.).

Method of tooth extraction. The animal was anesthetized, and the application site was cleaned with a 20 -fold diluted solution of povidone iodine. To prevent tooth break after tooth extraction, the tip of the tooth was rounded. Using a scalpel blade, the connective fibers and periodontal ligament were cut along the tooth from the free gingival sulcus. Using a fissures bar (Astrokaba HP, AS04, SHOFU Inc.) and a high-performance micro-engine (VOLVERE Vmax, NSK Co., Ltd.), P3 was mediodistally split into half. The distal root side was removed with dental extracting forceps and an elevator. When the bleeding did not stop, astriction was carried out. After removing the pulp of the mesial root with a reamer, the root canal was filled with gutta-percha points, and sealed with a root canal sealer (Dentalis). Then the socket portion was washed thoroughly with physiological saline with suction.

RCPhC1 bone graft application. Using a spatula, the $\mathrm{RCPhC1}$ bone graft $(8.5 \mathrm{mg})$ mixed with physiological saline $(30 \mu \mathrm{L})$ was applied to the socket part. One operator carried out this processing for all the groups. The degree of application (filling) was almost uniform. Because the socket was small, if the total amount could not be applied, the remaining amount was discarded. Then the application site was covered with a collagen membrane (Geistlich Bio-Gide), which was cut into pieces of about $3 \times 4 \mathrm{~mm}$ (according to the presence or absence of the collagen membrane of the group configuration). After the application, the gingiva was sutured with nylon thread (5-0, Alfresa Pharma Corporation).

Treatment after RCPhC1 bone graft application. Administration was performed using a disposable polypropylene syringe (Terumo Corporation) fitted with an injection needle (Terumo Corporation). The animals were injected intramuscularly into the thigh muscle with sodium ampicillin solution at $500 \mathrm{mg} / 2.5 \mathrm{~mL} /$ body twice a day, once in the morning and once in the afternoon, from 0 to 3 days after application; on the day of application, they were treated once after application at $500 \mathrm{mg} / 2.5 \mathrm{~mL} /$ body. The animals were also treated subcutaneously with a Rimadyl injection at $4.4 \mathrm{mg} / \mathrm{kg}(0.09 \mathrm{~mL} / \mathrm{kg}$ as the formulation) once a day from 0 to 3 days after application. The day after application, the animals were injected subcutaneously into the back of the neck with sodium ampicillin in 5\% glucose lactated Ringer's solution at $100 \mathrm{~mL} /$ body twice a day, once in the morning and once in the afternoon. The sutures were removed up to 3 weeks after application.

In addition, during the 3 months after tooth extraction and application, the sites around the extraction/application of all the animals (except the non-treatment animals) were brushed in the afternoon at a frequency of more than three times a week.

Histology. Eight (8) paired $\mathrm{RCPhC1}$ grafted and control bone samples were harvested at 1,3 , and 6 months after surgery. Under general anesthesia, animals were quickly sacrificed with exsanguination. After saline $(70 \mathrm{~mL}$ each) was injected into both carotid arteries, neutralized formalin saline solution ( $35 \mathrm{ml}$ each side, $20 \%$, $\mathrm{pH}$ 7.2) was injected into both carotid arteries to complete perfusion fixation. The mandibles were harvested and post-fixed with buffered formalin. The mandibular specimens were decalcified and embedded in paraffin followed by histological preparation. The histological sections were prepared using narrow wires placed as size and orientation references. The histological sections were stained with H\&E. The resultant histological specimens were photographed via a standard upright microscope.

Data visualization. Data were visualized with Microsoft Excel 2007 (12.0.6787.5000) SP3 MSO (12.0.6785.5000), R version 3.6.2, or GraphPad Prism version 5.04 .

Statistics and reproducibility. Tukey's multiple comparison test was performed for rat calvarial model using GraphPad Prism version 5.04. Two-sided paired $t$-test was performed for canine tooth extraction model using $\mathrm{R}$ version 3.6.2. 


\section{Data availability}

The data that support the findings of this study are available from the corresponding author upon reasonable request.

Received: 22 July 2020; Accepted: 20 October 2020;

Published online: 20 November 2020

\section{References}

1. Siddiqui, J. A. \& Partridge, N. C. Physiological bone remodeling: systemic regulation and growth factor involvement. Physiology (Bethesda) 31, 233-245 (2016).

2. Dimitriou, R., Jones, E., McGonagle, D. \& Giannoudis, P. V. Bone regeneration: current concepts and future directions. BMC Med. 9, 66 (2011).

3. Giannoudis, P. V., Dinopoulos, H. \& Tsiridis, E. Bone substitutes: an update. Injury 36, S20-S27 (2005).

4. Mauffrey, C., Madsen, M., Bowles, R. J. \& Seligson, D. Bone graft harvest site options in orthopaedic trauma: a prospective in vivo quantification study. Injury 43, 323-326 (2012).

5. Azi, M. L. et al. Autologous bone graft in the treatment of post-traumatic bone defects: a systematic review and meta-analysis. BMC Musculoskelet. Disord. 17, 465 (2016).

6. Sohn, H. S. \& Oh, J. K. Review of bone graft and bone substitutes with an emphasis on fracture surgeries. Biomater. Res. 23, 9 (2019).

7. Rasch, A. et al. Evaluation of bone allograft processing methods: Impact on decellularization efficacy, biocompatibility and mesenchymal stem cell functionality. PLoS ONE 14, e0218404 (2019).

8. Zhang, H. et al. Demineralized bone matrix carriers and their clinical applications: an overview. Orthop. Surg. 11, 725-737 (2019).

9. Boyce, T., Edwards, J. \& Scarborough, N. Allograft bone. The influence of processing on safety and performance. Orthop. Clin. North Am. 30, 571-581 (1999).

10. Zamborsky, R., Svec, A., Bohac, M., Kilian, M. \& Kokavec, M. Infection in bone allograft transplants. Exp. Clin. Transplant. 14, 484-490 (2016).

11. Buser, Z. et al. Synthetic bone graft versus autograft or allograft for spinal fusion: a systematic review. J. Neurosurg. Spine 25, 509-516 (2016).

12. Sheikh, Z. et al. Natural graft tissues and synthetic biomaterials for periodontal and alveolar bone reconstructive applications: a review. Biomater. Res. 21, 9 (2017).

13. Parry, D. A. The molecular and fibrillar structure of collagen and its relationship to the mechanical properties of connective tissue. Biophys. Chem. 29, 195-209 (1988).

14. Marini, J. C. et al. Osteogenesis imperfecta. Nat. Rev. Dis. Primers 3, 17052 (2017).

15. Morello, R. Osteogenesis imperfecta and therapeutics. Matrix Biol. 71-72, 294-312 (2018).

16. Chowdhury, S. R. et al. Collagen type I: a versatile biomaterial. Adv. Exp. Med. Biol. 1077, 389-414 (2018).

17. Lucchese, G., Stufano, A., Trost, B., Kusalik, A. \& Kanduc, D. Peptidology: short amino acid modules in cell biology and immunology. Amino Acids 33, 703-707 (2007).

18. Clare, J. J., Rayment, F. B., Ballantine, S. P., Sreekrishna, K. \& Romanos, M. A. High-level expression of tetanus toxin fragment $\mathrm{C}$ in Pichia pastoris strains containing multiple tandem integrations of the gene. Biotechnology (N. Y.) 9 , 455-460 (1991).

19. Cregg, J. M., Vedvick, T. S. \& Raschke, W. C. Recent advances in the expression of foreign genes in Pichia pastoris. Biotechnology (N. Y.) 11, 905-910 (1993).

20. Boraston, A. B., Warren, R. A. \& Kilburn, D. G. Glycosylation by Pichia pastoris decreases the affinity of a family 2 a carbohydrate-binding module from Cellulomonas fimi: a functional and mutational analysis. Biochem. J. 358, 423-430 (2001).

21. Ahmad, M., Hirz, M., Pichler, H. \& Schwab, H. Protein expression in Pichia pastoris: recent achievements and perspectives for heterologous protein production. Appl. Microbiol. Biotechnol. 98, 5301-5317 (2014).

22. Vogl, T., Hartner, F. S. \& Glieder, A. New opportunities by synthetic biology for biopharmaceutical production in Pichia pastoris. Curr. Opin. Biotechnol. 24, 1094-1101 (2013).

23. Lommel, M. \& Strahl, S. Protein O-mannosylation: conserved from bacteria to humans. Glycobiology 19, 816-828 (2009).

24. Jacobs, P. P., Geysens, S., Vervecken, W., Contreras, R. \& Callewaert, N. Engineering complex-type N-glycosylation in Pichia pastoris using GlycoSwitch technology. Nat. Protoc. 4, 58-70 (2009).

25. Tuin, A., Kluijtmans, S. G., Bouwstra, J. B., Harmsen, M. C. \& Van Luyn, M. J. Recombinant gelatin microspheres: novel formulations for tissue repair? Tissue Eng. Part A 16, 1811-1821 (2010).
26. Parvizi, M. et al. Development of recombinant collagen-peptide-based vehicles for delivery of adipose-derived stromal cells. J. Biomed. Mater. Res. A 104, 503-516 (2016).

27. Ramirez-Rodriguez, G. B. et al. Biomimetic mineralization of recombinant collagen type I derived protein to obtain hybrid matrices for bone regeneration. J. Struct. Biol. 196, 138-146 (2016).

28. McLaughlin, S. H. \& Bulleid, N. J. Molecular recognition in procollagen chain assembly. Matrix Biol. 16, 369-377 (1998).

29. Yannas, I. V. Emerging rules for inducing organ regeneration. Biomaterials 34, 321-330 (2013)

30. Dagalakis, N., Flink, J., Stasikelis, P., Burke, J. F. \& Yannas, I. V. Design of an artificial skin. Part III. Control of pore structure. J. Biomed. Mater. Res. 14, 511-528 (1980).

31. Pawelec, K. M., Husmann, A., Best, S. M. \& Cameron, R. E. Understanding anisotropy and architecture in ice-templated biopolymer scaffolds. Mater. Sci. Eng. C Mater. Biol. Appl. 37, 141-147 (2014).

32. Schoof, H., Apel, J., Heschel, I. \& Rau, G. Control of pore structure and size in freeze-dried collagen sponges. J. Biomed. Mater. Res. 58, 352-357 (2001).

33. Pawelec, K. M. et al. Osteogenesis and mineralization of mesenchymal stem cells in collagen type I-based recombinant peptide scaffolds. J. Biomed. Mater. Res. A 105, 1856-1866 (2017).

34. Pawelec, K. M., van Boxtel, H. A. \& Kluijtmans, S. Ice-templating of anisotropic structures with high permeability. Mater. Sci. Eng. C Mater. Biol. Appl. 76, 628-636 (2017).

35. Fotticchia, A., Musson, D., Lenardi, C., Demirci, E. \& Liu, Y. Anisotropic cytocompatible electrospun scaffold for tendon tissue engineering elicits limited inflammatory response in vitro. J. Biomater. Appl. 33, 127-139 (2018).

36. Wu, Y. et al. Mechanically-enhanced three-dimensional scaffold with anisotropic morphology for tendon regeneration. J. Mater. Sci. Mater. Med. 27, 115 (2016).

37. Li, G. et al. Construction of biofunctionalized anisotropic hydrogel micropatterns and their effect on Schwann cell behavior in peripheral nerve regeneration. ACS Appl. Mater. Interfaces 11, 37397-37410 (2019).

38. Gomes, P. S. \& Fernandes, M. H. Rodent models in bone-related research: the relevance of calvarial defects in the assessment of bone regeneration strategies. Lab Anim. 45, 14-24 (2011).

39. Cooper, G. M. et al. Testing the critical size in calvarial bone defects: revisiting the concept of a critical-size defect. Plast. Reconstr. Surg. 125, 1685-1692 (2010).

40. Fan, H. et al. Cartilage regeneration using mesenchymal stem cells and a PLGA-gelatin/chondroitin/hyaluronate hybrid scaffold. Biomaterials 27, 4573-4580 (2006)

41. Liu, X., Smith, L. A., Hu, J. \& Ma, P. X. Biomimetic nanofibrous gelatin/apatite composite scaffolds for bone tissue engineering. Biomaterials 30, 2252-2258 (2009).

42. van Oosten, A. S. et al. Uncoupling shear and uniaxial elastic moduli of semiflexible biopolymer networks: compression-softening and stretchstiffening. Sci. Rep. 6, 19270 (2016).

43. Jones, C. A., Liang, L., Lin, D., Jiao, Y. \& Sun, B. The spatial-temporal characteristics of type I collagen-based extracellular matrix. Soft Matter 10, 8855-8863 (2014).

44. Alberti, K. A. \& Xu, Q. Biocompatibility and degradation of tendon-derived scaffolds. Regen. Biomater. 3, 1-11 (2016).

45. Charulatha, V. \& Rajaram, A. Influence of different crosslinking treatments on the physical properties of collagen membranes. Biomaterials 24, 759-767 (2003).

46. Ibusuki, S. et al. Photochemically cross-linked collagen gels as threedimensional scaffolds for tissue engineering. Tissue Eng. 13, 1995-2001 (2007).

47. Gutierrez, M. C., Ferrer, M. L. \& del Monte, F. Ice-templated materials: sophisticated structures exhibiting enhanced functionalities obtained after unidirectional freezing and ice-segregation-induced self-assembly. Chem. Mater. 20, 634-648 (2008).

48. Cardaropoli, G., Araujo, M. \& Lindhe, J. Dynamics of bone tissue formation in tooth extraction sites. An experimental study in dogs. J. Clin. Periodontol. 30, 809-818 (2003).

49. Stumbras, A., Kuliesius, P., Januzis, G. \& Juodzbalys, G. Alveolar ridge preservation after tooth extraction using different bone graft materials and autologous platelet concentrates: a systematic review. J. Oral. Maxillofac. Res. 10, e2 (2019)

50. Araujo, M. G. \& Lindhe, J. Socket grafting with the use of autologous bone: an experimental study in the dog. Clin. Oral Implants Res. 22, 9-13 (2011).

51. Orti, V. et al. Benefits of mineralized bone cortical allograft for immediate implant placement in extraction sites: an in vivo study in dogs. J. Periodontal. Implant. Sci. 46, 291-302 (2016).

52. Araujo, M., Linder, E. \& Lindhe, J. Effect of a xenograft on early bone formation in extraction sockets: an experimental study in dog. Clin. Oral Implants Res. 20, 1-6 (2009). 
53. Ho, K. N. et al. A novel HA/beta-TCP-collagen composite enhanced new bone formation for dental extraction socket preservation in beagle dogs. Materials (Basel) 9, 191 (2016).

54. Araujo, M. G. \& Lindhe, J. Ridge preservation with the use of Bio-Oss collagen: a 6-month study in the dog. Clin. Oral Implants Res. 20, 433-440 (2009).

55. Antoine, E. E., Vlachos, P. P. \& Rylander, M. N. Review of collagen I hydrogels for bioengineered tissue microenvironments: characterization of mechanics, structure, and transport. Tissue Eng. Part B Rev. 20, 683-696 (2014).

56. Felician, F. F., Xia, C., Qi, W. \& Xu, H. Collagen from marine biological sources and medical applications. Chem. Biodivers. 15, e1700557 (2018).

57. Liu, D., Nikoo, M., Boran, G., Zhou, P. \& Regenstein, J. M. Collagen and gelatin. Annu. Rev. Food Sci. Technol. 6, 527-557 (2015).

58. Ramirez-Rodriguez, G. B. et al. Biomineralized recombinant collagen-based scaffold mimicking native bone enhances mesenchymal stem cell interaction and differentiation. Tissue Eng. Part A 23, 1423-1435 (2017).

59. Nakamura, K. CellSaic, a cell aggregate-like technology using recombinant peptide pieces for MSC transplantation. Curr. Stem Cell Res. Ther. 14, 52-56 (2019).

60. Hong, S. J. et al. The effect of a fibrin-fibronectin/beta-tricalcium phosphate/ recombinant human bone morphogenetic protein-2 system on bone formation in rat calvarial defects. Biomaterials 27, 3810-3816 (2006).

61. Cowan, C. M. et al. MicroCT evaluation of three-dimensional mineralization in response to BMP-2 doses in vitro and in critical sized rat calvarial defects. Tissue Eng. 13, 501-512 (2007).

62. Schofer, M. D. et al. Electrospun PLLA nanofiber scaffolds and their use in combination with BMP-2 for reconstruction of bone defects. PLoS ONE 6, e25462 (2011).

63. Saito, A. et al. Targeted reversion of induced pluripotent stem cells from patients with human cleidocranial dysplasia improves bone regeneration in a rat calvarial bone defect model. Stem Cell Res. Ther. 9, 12 (2018).

64. Deng, Y. et al. Repair of calvarial bone defect using Jaridla-knockdown bone mesenchymal stem cells in rats. Tissue Eng. Part A 24, 711-718 (2018).

65. Wang, Y. Y., Ma, S., Chen, Q., Jiao, D. \& Yang, Y. In vivo selection with lentiviral expression of $\mathrm{Bcl} 2(\mathrm{~T} 69 \mathrm{~A} / \mathrm{S} 70 \mathrm{~A} / \mathrm{S} 87 \mathrm{~A})$ mutant in hematopoietic stem cell-transplanted mice. Gene Ther. 25, 220-233 (2018).

66. Hsieh, M. K. et al. BMP-2 gene transfection of bone marrow stromal cells to induce osteoblastic differentiation in a rat calvarial defect model. Mater. Sci. Eng. C Mater. Biol. Appl. 91, 806-816 (2018).

67. Bass, A. S., Tomaselli, G., Bullingham, R. 3rd \& Kinter, L. B. Drugs effects on ventricular repolarization: a critical evaluation of the strengths and weaknesses of current methodologies and regulatory practices. J. Pharmacol. Toxicol. Methods 52, 12-21 (2005).

68. Schreiner, A. J. et al. Comparison of meniscal allograft transplantation techniques using a preclinical canine model. J. Orthop. Res. https://doi.org/ $10.1155 / 2020 / 8894449$ (2020) In press.

69. Ge, J. et al. Comparison of different grafting materials for treatment of bone defect distal to the molar in canine. Clin. Implant. Dent. Relat. Res. 20, 444-454 (2018).

70. Calvo-Guirado, J. L. et al. Socket-shield technique: the influence of the length of the remaining buccal segment of healthy tooth structure on peri-implant bone and socket preservation. A study in dogs. Ann. Anat. 221, 84-92 (2019).
71. Samandari, M. H. et al. Socket preservation using freeze-dried bone allograft with and without plasma rich in growth factors in dogs. Dent. Res. J. (Isfahan) 13, 432-439 (2016).

72. Atieh, M. A. et al. Interventions for replacing missing teeth: alveolar ridge preservation techniques for dental implant site development. Cochrane Database Syst. Rev. CD010176 (2015).

\section{Author contributions}

I.N. initiated and supervised the project. H.F. designed and interpreted material experiments, prepared, and analyzed materials. T.H. designed and interpreted animal experiments, performed rat and canine surgeries. A.O. analyzed, and visualized microCT data. Y.O. helped freezing experiments. I.O. performed mechanical testing. H.F. and I.N wrote the manuscript with input from the other authors.

\section{Competing interests}

I.N. consulted for and was paid by FUJIFILM Corporation. FUJIFILM Corporation filed patents: WO2011/027850 (Bone Regeneration Agent including Gelatin); WO2013/ 137268 (Method for Producing Tissue Repair Material); and WO2014/141877 (Tissue Repair Material). They disclosed bone graft materials related to the materials reported herein. The other authors have no competing interests.

\section{Additional information}

Supplementary information is available for this paper at https://doi.org/10.1038/s43246020-00089-9.

Correspondence and requests for materials should be addressed to H.F.

Peer review information Primary handling editor: John Plummer.

Reprints and permission information is available at http://www.nature.com/reprints

Publisher's note Springer Nature remains neutral with regard to jurisdictional claims in published maps and institutional affiliations.

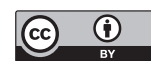

Open Access This article is licensed under a Creative Commons Attribution 4.0 International License, which permits use, sharing, adaptation, distribution and reproduction in any medium or format, as long as you give appropriate credit to the original author(s) and the source, provide a link to the Creative Commons license, and indicate if changes were made. The images or other third party material in this article are included in the article's Creative Commons license, unless indicated otherwise in a credit line to the material. If material is not included in the article's Creative Commons license and your intended use is not permitted by statutory regulation or exceeds the permitted use, you will need to obtain permission directly from the copyright holder. To view a copy of this license, visit http://creativecommons.org/ licenses/by/4.0/.

(C) The Author(s) 2020, corrected publication 2020 